\title{
Influencia de la realidad socioeconómica de Galicia en la dinámica de producción de incendios forestales
}

Socioeconomic reality of Galicia and dynamics of forest fire production

\author{
Jaime de Diego Abad \\ jdediego@comillas.edu \\ Instituto Universitario de estudios sobre Migraciones \\ Universidad Pontificia Comillas (España) \\ Mercedes Fernández García \\ mercedes@comillas.edu \\ Instituto Universitario de estudios sobre Migraciones \\ Universidad Pontificia Comillas (España)

\section{Antonio Rúa Vieites} \\ rvieites@icade.comillas.edu
}

Facultad de Económicas y Administración y Dirección de Empresas

Universidad Pontificia Comillas (España)

\section{Resumen}

Galicia, con un 5,8\% de la superficie de España, concentró el 50\% de los incendios forestales del país en el siglo XXI. Las investigaciones han analizado principalmente las características físicas y meteorológicas, las situaciones post- incendio y sus capacidades destructivas. Los factores socioeconómicos existentes antes del incendio en los territorios afectados han sido 
menos estudiados. Este artículo analiza la dinámica de los incendios forestales en Galicia entre 2001 y 2015. Concretamente, examina las tendencias espaciotemporales de su ocurrencia, la superficie afectada y la relación entre los incendios forestales y las características socioeconómicas de los distintos municipios gallegos. Para ello se realizó un análisis descriptivo exploratorio y un modelo de regresión lineal múltiple con dos variables dependientes diferentes, las Hectáreas quemadas y la Intensidad de los incendios; las variables independientes incluyeron tanto factores ambientales como aquellos aspectos socioeconómicos más relevantes. Los resultados muestran que existe una relación entre determinadas variables socioeconómicas indicativas de vulnerabilidad social (envejecimiento, tasa de masculinidad, baja densidad poblacional o pérdida de valor catastral) y los incendios forestales. Estos resultados pueden resultar de utilidad para la mejora en el diseño de acciones de prevención de incendios por parte de las autoridades responsables.

Palabras clave: incendios forestales; variables socioeconómicas; Galicia.

\begin{abstract}
Galicia, with $5.8 \%$ of the surface of Spain, concentrated $50 \%$ of the wildfires in the 21 st century. Current researches have mainly addressed the physical and meteorological characteristics, the post-fire situations and their destructive capacities. The socioeconomic factors existing before the fire have been less studied. This article analyzes the dynamics of forest fires in Galicia between 2001 and 2015: the spatial-temporal trends, the affected areas and their relationship with the socioeconomic characteristics of the different Galician municipalities. To this end, (1) exploratory descriptive analysis and (2) a multiple linear regression model with two different dependent variables -the hectares burned and the virulence of the fires- were carried out; the independent variables included both, environmental factors and socioeconomic aspects. The results show that there is a relationship between socioeconomic variables indicative of social vulnerability lageing, rate of masculinity, low population density or loss of cadastral value) and forest fires. These results can help improve the design of fire prevention actions by public authorities.
\end{abstract}

Keywords: wildfires; socioeconomic variables; Galicia.

\title{
1 Introducción
}

Los incendios forestales son desastres naturales que están asociados mayormente a regiones con características climatológicas determinadas y una vegetación propensa al fuego. España se sitúa 
dentro de los países más afectados anualmente por estos eventos, entre los que destacan Estados Unidos y Australia. De hecho, en los Estados Unidos, los incendios forestales han aumentado su tamaño y potencial destructivo (Ager et al., 2017) y en Australia, en el siglo pasado, los incendios en pastizales fueron el cuarto mayor riesgo asociado a las catástrofes, después de las olas de calor (Haynes et al., 2010). A pesar de ser considerados un desastre natural, el origen de los incendios forestales es generalmente antrópico, llegando esta causa a configurar el 96 \% de los casos en España (Hernández, 2016).

Por este motivo, un gran desafío estriba en establecer la unión entre todos los factores que intervienen en un incendio forestal, desde la prevención hasta la extinción, entendiendo su comportamiento y minimizando sus efectos.

Sin embargo, la perspectiva que se ha venido tomando tradicionalmente en el ámbito mundial para la lucha contra incendios se ha centrado en las situaciones post-incendio y sus potenciales capacidades destructivas -áreas quemadas, tipo de vegetación afectada, pérdidas económicas, etc- (Kocher \& Butsic, 2017). Por estas razones, como se señala más adelante en este trabajo, la investigación actual sobre incendios forestales está enfocada principalmente a analizar sus características físicas o meteorológicas.

Por lo que respecta a las cuestiones referidas a los estadios anteriores a la producción del incendio, como la prevención, la minimización o la mitigación de sus efectos, es necesario conocer aquellas cuestiones que influyen en las características de los grupos sociales en los entornos en los que tienen lugar dichos incendios (Murphy, 2005). Estaríamos hablando de una serie de factores socioeconómicos (estructura y densidad de la población, renta per cápita, PIB, entre otros) que caracterizan a la población residente en los lugares donde se produce el fuego. Sin embargo, la investigación académica ha profundizado en menor medida en este tipo de factores. Analizar estas variables resulta crucial en el ámbito de la investigación sobre incendios forestales (Padilla \& Vega-García, 2011), pues permite centrar la atención en aquellas cuestiones clave para lograr una mayor incidencia en las actuaciones de minimización de la producción y/o prevención de los mismos.

Los patrones naturales de los incendios se ven alterados por causas antrópicas que afectan al terreno, la climatología o a las poblaciones existentes. Este hecho puede magnificar los efectos negativos del fuego, generando grandes catástrofes naturales con consecuencias muy negativas para el entorno (Bentley \& Penman, 2017). En este sentido, las zonas donde existen 
características socioeconómicas adversas pueden resultar muy relevantes para determinar y predecir la ocurrencia de los incendios forestales.

En España, la Comunidad Autónoma de Galicia ha sido la región que ha acaparado el mayor número de incendios forestales en lo que va de siglo XXI. Según los estudios especializados que se analizan posteriormente en este artículo (Barreal et al., 2011; Barreal et al., 2012; Balsa \& Hermosilla, 2013; Loureiro \& Barreal, 2015), los incendios forestales en esta comunidad autónoma están directamente relacionados tanto con factores socioeconómicos conexos a la vulnerabilidad social (el envejecimiento poblacional o la baja densidad de población unida al escaso desarrollo económico) como con factores naturales o medioambientales (la ganadería extensiva, las zonas abandonadas o las zonas de interfaz urbano forestal). Ello indudablemente refuerza la necesidad tanto de investigar la relación entre las variables socioeconómicas y los incendios forestales de esta región, como de encontrar qué variables son más determinantes en su producción.

Este artículo tiene un doble objetivo:

- Estudiar la distribución espacial de las áreas recorridas por los incendios forestales (Hectáreas quemadas y Ratio hectáreas/nº de incendios) en Galicia. Se estudiará primero, el comportamiento agregado temporalmente desde el 2001 al 2015 por municipio y posteriormente, se analizará mediante un análisis de tendencia, el comportamiento desagregado por año.

- Establecer la relación entre las variables socioeconómicas y medioambientales seleccionadas en referencia a los municipios gallegos y (1) las Hectáreas quemadas y (2) el ratio hectáreas $/ \mathrm{n}^{\circ}$ de incendios ocurridos o intensidad, desde 2001 a 2015.

Para dar cuenta de los objetivos anteriores el presente artículo se estructurará de la forma siguiente: en primer lugar se analiza de manera general la dinámica de producción de los incendios forestales; a continuación se estudia el caso concreto de Galicia como comunidad autónoma más relevante dentro de España a la hora de hablar de incendios forestales. Además, se analizan las características socioeconómicas de esta comunidad autónoma. La tercera sección del artículo es metodológica y describe las variables concretas utilizadas para el modelo. Por ultimo en la discusión y posteriores conclusiones se demuestra la relevancia de los resultados que establecen una relación entre las variables socioeconómicas relacionadas con la vulnerabilidad social y las Hectáreas quemadas e intensidad de los incendios forestales. 


\section{Los incendios forestales}

En primer lugar, es necesario conocer las dinámicas que caracterizan a los incendios forestales y cuáles son los aspectos fundamentales de estos. Además, existen diferentes factores que afectan a los incendios forestales y que resultan de vital importancia para poder finalmente establecer la relación con los grupos humanos que están dentro de las zonas afectadas.

\subsection{Los incendios forestales y las dinámicas en su producción}

La concepción de incendio forestal difiere en función del contexto de que se trate. Así, desde el punto de vista del manejo forestal, se hablaría de la propagación libre y no programada del fuego sobre la vegetación silvestre (Rodríguez et al., 2010). Sin embargo, en ecología, los incendios son un disturbio (Rowe \& Sheard, 1981); es decir, una pérdida de individuos o biomasa, que se produce de forma repentina y eventual.

Desde el punto de vista ecológico, los incendios forestales provocan cambios globales que afectan a la biósfera y son la tercera causa en la pérdida y degradación de grandes extensiones de terrenos forestales. Son, además, una fuente significativa de las emisiones de gases de efecto invernadero y suponen la pérdida de millones de toneladas de carbono almacenado en los ecosistemas; influyen en el cambio de las características del suelo y la pérdida de biodiversidad; afectan al paisaje; impactan en el hábitat de la fauna y flora silvestre; e inciden en la disminución de la capacidad de retención de agua pluvial (Moritz et al., 2014; Gómez et al., 2015).

Sin embargo, el impacto de los incendios no siempre es negativo: el problema surge cuando su recurrencia supera la capacidad de resistencia de los ecosistemas, y se alteran de manera irreversible procesos naturales que sirven de base para la producción de bienes y servicios ambientales (Benítez-Badillo et al., 2010).

La mecánica de los incendios responde, fundamentalmente, a la concurrencia simultánea de tres elementos: oxígeno, combustible y la fuente de ignición (Crompton et al., 2010). No obstante, existen otras variables que resultan tan relevantes o más, como el cambio en las condiciones meteorológicas, la topografía y las actividades humanas en la zona (Birkmann, 2013). Esta última variable, la actividad humana -y su capacidad de alterar los ecosistemas, como los usos del suelo, agricultura y ganadería, nuevas construcciones, etc.- influye notablemente en la magnitud de los incendios, su capacidad destructiva y los efectos que pueden provocar en los sistemas circundantes (Moritz et al., 2014). 


\subsection{Factores que afectan a los incendios forestales}

Lo que convierte un evento natural en desastre está determinado por el territorio y la población que se sitúa en las zonas expuestas. Los incendios forestales son considerados desastres, siendo especialmente importantes en la zona mediterránea del sur de Europa. Dentro de estas áreas afectadas, las características sociales varían entre provincias, municipios, ciudades, clases, etc. Delimitar los riesgos derivados de los desastres se antoja complicado debido a esa variabilidad (Del Moral \& Pita, 2002); de hecho, las dimensiones de una catástrofe son múltiples y pueden clasificarse de la siguiente manera (Birkmann, 2013):

\section{a) Dimensión medioambiental}

Esta dimensión está relacionada con los efectos derivados de la destrucción medioambiental que produce cambios en el entorno natural, como el deshielo, la destrucción de barreras naturales en costas, emisión de gases, etc. Su análisis puede dividirse en dos grandes bloques: meteorológico y territorial (Birkmann, 2013).

La dimensión meteorológica no depende del hombre, salvo por su intervención en el cambio climático (lyalombe, 2011). La composición de la vegetación, la humedad, la temperatura, las precipitaciones, la composición del terreno o el viento, serían variables incluidas en este apartado.

Los usos del territorio (construcción, prácticas ganaderas, etc.) pueden alterar la composición del medio natural. Sin embargo, aunque este sea un recurso importante para las personas, es a la vez el origen de los procesos naturales que pueden causar un desastre (Molina et al., 2017).

\section{b) Dimensión socioeconómica}

Por una parte, en la vertiente social de esta dimensión, se tratan los aspectos de justicia, diferencias sociales y organización social, así como fortalezas individuales. En algunos estudios se tienen también en cuenta problemas como pobreza, marginalización social, demografía (grupos de edad vulnerables), educación, salud y bienestar, migraciones y percepción del riesgo (Donner \& Rodríguez, 2008). Los factores que determinan esta dimensión dependen de condiciones específicas y procesos de desarrollo muy diferentes en función del país o región analizados, así como del tipo de peligro a encarar (Bergstrand et al., 2015).

Los aspectos de índole económica se refieren a la ocupación, ingresos, efectos económicos, consumo, propiedades inmobiliarias y ahorros (Ashe et al., 2009). En esta dimensión se pueden introducir también cuestiones de habitabilidad y vivienda. Asimismo, se tiene en cuenta el medio 
de subsistencia de ciertos habitantes, que puede ser muy relevante en aquellos casos basados especialmente el sector primario (agricultura, pesca, etc.) por su clara conexión con el medio natural (Elliott \& Pais, 2010).

\subsection{El papel de los grupos humanos en la producción de incendios}

Los grupos sociales con ciertas características propias de vulnerabilidad social son los que mayor riesgo presentan de sufrir los efectos de una catástrofe (Cirella et al., 2016). Las características socioeconómicas de una persona (clase, grupo étnico de pertenencia, sexo o nivel de pobreza) - grupo de personas (desigualdades en la estructura social o económica) influyen en su capacidad de anticipar, enfrentar, resistir y recuperarse del impacto de un desastre natural (Wisner et al., 2004; Morrow, 1999). Las personas en situación de vulnerabilidad presentan una mayor tendencia a encontrarse ante escenarios en los que se empeoren sus circunstancias adversas (Fogel, 2017).

Por otra parte, dentro de un desastre natural, como los incendios forestales, entran en juego ciertos procesos sociales, económicos y políticos; por este motivo, las actuaciones preventivas deben poner el énfasis en las características de las personas. Ello refuerza la idea de estudiar las particularidades de las poblaciones en el análisis de riesgo de incendios forestales y no solo fijarse en los efectos post catástrofe (Alonso, 2002). Las variables socioeconómicas son, por tanto, muy importantes para determinar y predecir la ocurrencia y efectos de los incendios forestales, teniendo en cuenta que la recuperación será muy diferente dependiendo del colectivo vulnerable al que dicho desastre afecte (Paveglio et al., 2016).

Los factores humanos como causa de los incendios forestales son muy relevantes dentro de la Europa mediterránea y en concreto, en España (Martínez-Fernández et al., 2013). Uno de los rasgos más importantes de los incendios forestales es su aleatoriedad. Por ello, resulta tan complicado predecir el comportamiento de un incendio, así como dónde y cuándo dará comienzo (Paveglio et al., 2018).

Los cambios en la climatología que se están produciendo actualmente, así como los cambios en los usos del territorio, son aspectos desfavorables de cara a la reducción del riesgo de incendios forestales en España, ya que influyen en la ocurrencia y en la intensidad. Se prevé un aumento de episodios que superen las capacidades de los dispositivos de extinción que puedan llegar a convertirse en situaciones de emergencia nacional (Moreno, 2014).

Aunque de los incendios se derivan, en algunos casos, consecuencias favorables para la biodiversidad y las características ecológicas de un espacio, a la larga acaban produciéndose 
grandes costes económicos y sociales (Crompton et al., 2010). Dichos costes han aumentado considerablemente en los últimos años en las zonas intermedias entre lo urbano y lo forestal (Bouillon et a.l, 2014). Estudios recientes demuestran una correlación positiva entre los gastos realizados en prevención de incendios y la presencia de terrenos privados y edificables (Stein et al., 2013)

\section{Los incendios forestales en España: el caso de Galicia}

Galicia es la región más al noroeste de la península lbérica, un territorio de un poco más de $29000 \mathrm{Km}^{2}$, que presenta un alto porcentaje de monte y bosque, aproximadamente un 69\%, la mayor parte abandonado y lleno de maleza. Galicia cuenta con una de las más extensas superficies forestales desaprovechadas, hasta un 30 \% de su territorio (Beramendi, 2018, April 15). De los algo más de dos millones de hectáreas de monte, hay 600000 que no se encuentran arboladas, lo que quiere decir que una gran parte del territorio forestal está infrautilizado para usos industriales. Este porcentaje es más del doble que el estimado en países como Finlandia o Austria, y también muy superior al de Suecia o Estados Unidos.

Galicia ha sido la comunidad autónoma española más afectada por los incendios forestales desde comienzos del siglo XXI (Loureiro \& Barreal, 2015). Además, los últimos informes demuestran que las temporadas de incendios se están alargando y que, dentro de Europa, el norte de España y Portugal, son las áreas más críticas (San-Miguel-Ayanz et al., 2017).

Los incendios forestales se reconocen como uno de los problemas ambientales más importantes dentro de Galicia (Balsa y Hermosilla, 2013). Suponen un impacto de gran envergadura para el sector económico y provocan grandes riesgos para las personas y ecosistemas, todo ello unido al gasto público que suponen (Hernández, 2016).

Según los estudios especializados (Barreal et al., 2011), los incendios forestales en Galicia están directamente relacionados con una mezcla entre factores naturales o medioambientales y factores socioeconómicos. Dichos factores se pueden considerar bien conocidos y predecibles (Cardil et al., 2013), pero superan normalmente las capacidades de los medios de extinción. Los analizamos por separado a continuación.

\subsection{Factores medioambientales}

a) Variables meteorológicas 
La producción vegetal que caracteriza el territorio gallego ${ }^{1}$ confiere a las zonas rurales y zonas cercanas a núcleos urbanos una gran capacidad de regeneración de especies arbustivas. Esto es debido a sus características edafológicas y climatológicas. Ante altas temperaturas, bajo grado de humedad y velocidad del viento elevada, este combustible tiene un grado de peligrosidad alto en lo que a incendios forestales se refiere. Además, la velocidad de propagación es más elevada, viéndose favorecidas las reproducciones de focos iniciales y un avance muy rápido para la extinción directa (Ponte \& Bandín, 2008).

Las variables medioambientales extremas son importantes en la ocurrencia de incendios forestales: la humedad relativa, la temperatura máxima y la velocidad del viento suponen, en circunstancias especiales, un factor agravante de las consecuencias catastróficas de los incendios (Rodríguez \& Ramil-Rego, 2007; Martínez-Fernández et al., 2013). Los informes elaborados por Meteogalicia reflejan un aumento de los días calurosos en primavera (1,5 días por década) y en verano (2,5 días por década), y un aumento también de las noches cálidas en otoño. Todo ello conlleva un aumento de las olas de calor, que influye directamente en los incendios forestales, incrementando tanto la ocurrencia de estos eventos como la capacidad destructiva de los mismos. En resumen, se da un mayor horizonte temporal de ocurrencia, donde la época de peligro es más larga, incrementándose el riesgo al que se ven sometidos todos los elementos del territorio (Gonc,alves et al., 2012).

El aumento de las precipitaciones cuando el suelo esta desprotegido conlleva grandes pérdidas. Si no existe vegetación, debido a un incendio forestal, la erosión en las épocas de lluvias es mayor. Ello podría conducir a un empobrecimiento de los suelos por lavado de los nutrientes, pérdida de biodiversidad y disminución de la productividad, además de tener otros riesgos asociados como inundaciones y deslizamientos de tierra (Gonçalves et al., 2012).

\section{b) Variables territoriales}

Adicionalmente a los factores ambientales que se han descrito en párrafos anteriores, los usos del territorio en Galicia influyen también en la producción de incendios. En esta región, los terrenos son de tenencia mayormente privada (97,2\%). Dentro de estos terrenos privados el $32,7 \%$ es monte vecinal o en mancomunidad. El resto de las tierras se enmarca en otro tipo de

1 El terreno forestal gallego se puede considerar mayoritariamente arbolado, en torno al $70 \%$. Dentro de este territorio arbolado el $52 \%$ se describen como frondosas, tanto autóctonas como alóctonas. Las coníferas, en cambio, representan un $31 \%$ y el $17 \%$ restante es un bosque mixto donde se alternan coníferas y frondosas (PLADIGA, 2018). El objeto principal de este trabajo es analizar la influencia de las variables socioeconómicas en la producción de incendios forestales, por lo que no se profundiza en el estudio de los modelos de combustible. 
tenencia privada indeterminada, encontrándose muchos de estos terrenos abandonados o descuidados (Sineiro, 2006). El número de propietarios forestales, según el Plan Forestal de Galicia, está por encima de los 650000 y el tamaño medio de parcela es de 2-3 hectáreas; ello demuestra el importante fraccionamiento de las propiedades forestales en Galicia (PLADIGA, 2018).

El territorio gallego es complejo pues en él se combinan y alternan núcleos urbanos con edificaciones aisladas. A su vez coexisten zonas muy dinámicas, desde el punto de vista demográfico y económico, con otras más deprimidas. Pero incluso en estas últimas existen ciudades que actúan como dinamizadores de la región. Muchas casas de las zonas de conexión entre medio urbano y medio forestal están en alto de riesgo de incendio. Sin embargo, el potencial daño económico de estos eventos es mayor en algunos sitios en comparación con otros; esto es, la magnitud del daño depende no sólo de cuestiones de densidad de población y distribución de las viviendas sino de factores como la meteorología, los tipos de vegetación, los usos del territorio, etc. (Stein et al., 2013).

Por otra parte, las grandes superficies abandonadas por la agricultura y la falta de gestión de las parcelas tienen en la producción forestal un nicho de mercado importante, al mismo tiempo que se favorece la ordenación del monte rural y la lucha contra la desertización. El desconocimiento de las reglas más elementales de la lógica forestal y la falta de una educación ambiental adecuada producen un fuerte desajuste entre exigencias y comportamiento social (Vilariño, 1998). La causa de los incendios forestales en Galicia está directamente relacionada con costumbres arcaicas en áreas deprimidas o las negligencias en el uso del fuego como herramienta de gestión (Balsa y Hermosilla, 2013). Existe una gran ignorancia respecto a este tipo de catástrofes, una ausencia de conciencia y cultura forestal y, obviamente, intereses económicos asociados a los usos agrícolas y ganaderos que están directamente enfrentados a los terrenos forestales y su gestión (COSE, 2015). A largo plazo, estos desajustes producen un aumento de los incendios forestales y sus capacidades destructivas, produciendo una mayor degradación de las zonas naturales (Vilariño, 1998).

\subsection{Factores socioeconómicos}

a) Variables sociales

El despoblamiento rural es uno de los grandes problemas a los que se enfrenta España y en concreto Galicia, considerándose un fenómeno demográfico y territorial. De hecho, Galicia ha perdido con respecto a 2008 un 9,2 \% de su población rural (CES, 2018). 
Pero hay otros puntos críticos que se relacionan con la desertización demográfica del medio rural. Concretamente, la baja densidad presenta una serie de problemas asociados comunes, como son el envejecimiento, el aislamiento geográfico, la falta de integración territorial con otras zonas contiguas, la mala conexión y dificultad en el transporte, ausencia de servicios sociales adecuados, menores dotaciones de capital humano y oportunidades de empleo. Todo ello conduce inevitablemente a un declive económico (Bergstrand et al., 2015; Ballart et al.,2016) que también produce impactos medioambientales (Balsa \& Hermosilla, 2013).

El abandono de los usos tradicionales ganaderos y agrícolas supone un factor de riesgo para la conservación del medio natural. Esto es debido a que se producen transformaciones paisajísticas sin control del territorio forestal asociado al medio rural. En muchos casos, estos territorios se corresponden con parcelas particulares privadas (Wigtil et al., 2016).

La caída de la ganadería extensiva en España (un $30 \%$ entre 2004 y 2015) es un factor agravante en la producción de incendios forestales (CES, 2018); concretamente, la ganadería extensiva repercute sobre el paisaje forestal, favoreciendo los mosaicos y la reducción del combustible en los montes de Galicia (Rigueiro et al., 2002).

En resumen, el progresivo abandono de las zonas rurales produce efectos negativos sobre el medio ambiente, como por ejemplo la pérdida de suelo y la exposición de grandes superficies a fenómenos erosivos (Loureiro \& Barreal 2015). El riesgo de incendio producido por esta falta de gestión de los terrenos forestalesaumenta, además, debido a los usos tradicionales del fuego por parte de los ganaderos y agricultores (CES, 2018).

b) Variables económicas

Desde comienzos del siglo XXI, Galicia ha experimentado dos períodos diferenciados, sinérgicos a la situación de la economía española. En un primer período (2000-2008) se produjo un incremento importante de la renta per cápita industrial con el consecuente aumento de la renta per cápita y del consumo real por habitante y ascenso del PIB (Guisán \& Aguayo, 2009). En el segundo período (2008-2015), en cambio, tiene lugar una caída en diversos sectores productivos, traduciéndose en un descenso en la renta real por habitante y, por ende, en el PIB (Guisán, 2017).

Esta disminución del PIB ha producido, a su vez, una reducción del capital disponible para realizar actividades en todos los sectores, siendo uno de ellos la lucha contra incendios forestales. En este sentido, como indica Muñoz (2009), en materia de incendios forestales, se actúa en lo urgente (la extinción) y apenas quedan recursos para la prevención. Así, debido a la 
crisis acaecida en España, algunos ayuntamientos se han visto obligados a reducir la inversión en el avance de nuevas políticas y medidas necesarias para la lucha contra incendios forestales (Guisán, 2017).

Las cuestiones territoriales y sociales anteriormente mencionadas impactan también en las cuestiones económicas. Por ejemplo, la disminución sufrida en las cabezas de ganado bovino (y el consecuente cambio en los usos del territorio debido a la reducción de explotaciones ganaderas) - muestra su vertiente económica en la disminución del número de cabezas de ganado (Rigueiro et al, 2002) - . Por su parte, la cuestión social del abandono del medio rural y el envejecimiento de la población de estas regiones ha tenido como consecuencia la pérdida de valor de las parcelas consideradas rústicas, es decir no urbanizables, destinadas a la explotación agrícola, ganadera, forestal o de caza (Varela et al., 2007).

\section{Metodología}

\subsection{Objetivo de la investigación}

Como ya se ha mencionado anteriormente, los datos de las últimas décadas demuestran que, dentro de España, la comunidad Autónoma de Galicia es la que acapara la mayor parte da la ocurrencia de incendios (Balsa \& Hermosilla, 2013).

De todas las dimensiones que explican la producción de incendios en Galicia, han sido las variables medioambientales las más profusamente tratadas en la literatura (Muñoz, 2009; Cardil et al., 2013; Gonc,alves, 2012). Sin embargo, los estudios que abordan las dimensiones social o económica han sido mucho más escasos (Wigtil, 2016; Paveglio, 2016; Barreal et al., 2011).

Concretamente, de Diego et al. (2019) analizan la relación entre los aspectos socioeconómicos relacionados con la vulnerabilidad social que reflejan la realidad de los municipios gallegos y el número de incendios forestales ocurridos entre 2001 y 2015. El presente artículo amplía este espectro de análisis, desde una doble perspectiva: en primer lugar, centra la atención en otras dos variables vinculadas a la ocurrencia de incendios como son las Hectáreas quemadas y el Ratio hectáreas $/ \mathrm{n}^{\circ}$ de incendios (medida esta última del grado de intensidad de los incendios); además, añade nuevas variables explicativas, relacionadas con los aspectos meteorológicos. Una relación entre las variables socioeconómicas y los incendios forestales permite centrar la atención en aquellas cuestiones clave para lograr una mayor incidencia en las actuaciones de minimización de su producción y/o prevención de los mismos. 


\subsection{Fuentes}

Para poder realizar este análisis se necesita un conjunto de datos de calidad sobre los incendios ocurridos en Galicia. Estudios previos establecen diversos horizontes temporales: entre 20012006 (Barreal et al., 2011), 2001-2009 (Barreal et al., 2012), 2006 (Balsa \& Hermosilla, 2013) y 2001-2010 (Loureiro \& Barreal, 2015). En este sentido, dado que existía información disponible, se decidió ampliar el horizonte temporal de la investigación, seleccionándose los datos actualizados que abarcan desde 2001 hasta 2015. Se estableció la unidad observacional a nivel municipal para tener la mayor precisión posible que permitiera mostrar las diferencias del territorio (Barreal et al., 2011) y por ser la mínima unidad territorial de la que existe información socioeconómica precisa y uniforme.

Como se ha mencionado con anterioridad (Birkmann, 2013), las variables se pueden agrupar en dos grandes dimensiones: medioambiental y socioeconómica. La información sobre las variables medioambientales se obtuvo a partir del Banco de Datos de la Naturaleza (BDN) ${ }^{2}$ y Meteogalicia. ${ }^{3}$ Por lo que se refiere a las variables que componen la dimensión socioeconómica, estas se obtuvieron directamente a partir de la información estadística existente para cada uno de los municipios de la región, a través del Instituto Galego de Estatistica (IGE) ${ }^{4}$.

En la tabla 1 se describen las variables utilizadas para la elaboración de los modelos, atendiendo tanto a la revisión de la literatura como a la información disponible en las fuentes de datos reseñadas. Estas variables se han estructurado según las dimensiones antes descritas: meteorológica, territorial, social y económica. Cada una de las variables utilizadas representa un agregado de los 15 años, es decir, primero se han realizado la media y mediana anual y posteriormente se ha calculado una media agregada para este período de 15 años. Por este motivo, algunos valores de variables que deberían ser números enteros (por ejemplo, la población mayor de 64 años) presentan decimales. Esta información ha servido de base para realizar los posteriores análisis.

2 Para la obtención de los datos del BDN se realizó una petición a través de la página web: https://www.miteco.gob.es/es/biodiversidad/servicios/banco-datos-naturaleza/contacto-banco-datosnaturaleza/

3 El acceso a Meteogalicia permite ver la información a diferentes datos relacionados con la meteorología, teniendo también datos históricos: https://www.meteogalicia.gal/web/index.action

4 La consulta se realizó a través de las fichas municipales. https://www.ige.eu/igebdt/esq.jsp?paxina=002003001\&ruta=fichas/bdmunicipal_selec.jsp 
Tabla 1. Descripción de las variables utilizadas, por municipio

(media del período de 15 años analizado)

\begin{tabular}{|c|c|c|c|c|c|c|}
\hline Dimensión & Variables & Min. & Max. & Media & $\begin{array}{l}\text { Desviación } \\
\text { típica }\end{array}$ & Descripción \\
\hline \multirow{3}{*}{  } & MediaTaEST & 19,2 & 22,9 & 22,5 & 0,64 & $\begin{array}{l}\text { Media de la temperatura en } \\
\text { época estival, en grados } \\
\text { centígrados }\end{array}$ \\
\hline & MediaHaEST & 62,4 & 80,1 & 66,7 & 3,82 & $\begin{array}{l}\text { Media de la humedad relativa en } \\
\text { época estival en porcentaje }\end{array}$ \\
\hline & MediaVoEST & 3,52 & 7,51 & 4,60 & 0,35 & $\begin{array}{l}\text { Media de la velocidad del viento } \\
\text { en época estival en } \\
\text { metros/segundo }\end{array}$ \\
\hline \multirow{3}{*}{  } & DisNucleos & 0 & 116,00 & 4,81 & 11,17 & $\begin{array}{l}\text { Número de construcciones } \\
\text { individuales aisladas dividido } \\
\text { entre el número de } \\
\text { aglomeraciones con menos de } \\
\text { diez construcciones }\end{array}$ \\
\hline & Ganaderías & 0 & 5 & 1 & 1 & $\begin{array}{l}\text { Número de granjas ganaderas } \\
\text { de vacuno }\end{array}$ \\
\hline & HaRústicas & 0,47 & 1,00 & 0,95 & 0,07 & $\begin{array}{l}\text { Hectáreas rusticas (no } \\
\text { urbanizable, destinadas a la } \\
\text { explotación agrícola, ganadera, } \\
\text { forestal o de caza) }\end{array}$ \\
\hline \multirow{6}{*}{ 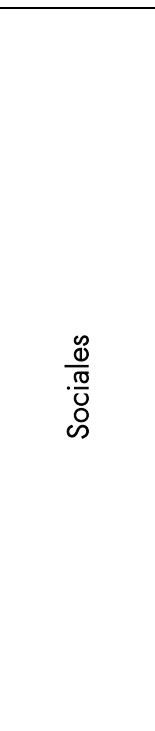 } & Población>64 & 76,91 & 51034,37 & 1932,85 & 4554,10 & $\begin{array}{l}\text { Número de personas mayores } \\
\text { de } 64 \text { años }\end{array}$ \\
\hline & Densidad & 0,03 & 64,61 & 1,44 & 4,26 & $\begin{array}{l}\text { Número de personas por } \\
\text { hectárea }\end{array}$ \\
\hline & I. Remplazo & 0,72 & 5,85 & 1,79 & 0,68 & $\begin{array}{l}\text { Índice de remplazo: Cociente } \\
\text { entre la población de } 60 \text { a } 64 \\
\text { años y la población de } 15 \text { a } 19 \\
\text { años. Mide la capacidad para } \\
\text { reemplazar a las personas que } \\
\text { se jubilan }\end{array}$ \\
\hline & I. Masculinidad & 0,83 & 1,29 & 0,96 & 0,05 & $\begin{array}{l}\text { Indice de masculinidad: } \\
\text { Cociente entre el número de } \\
\text { hombres y mujeres. }\end{array}$ \\
\hline & I. RecACT & 72,40 & 177,34 & 118,78 & 19,43 & $\begin{array}{l}\text { Indice de estructura de } \\
\text { población activa: cociente entre } \\
\text { la población de } 40 \text { a } 64 \text { años y } \\
\text { la población de } 15 \text { a } 39 \text { años. }\end{array}$ \\
\hline & PoblaciónEXT & 0 & 2,22 & 0,03 & 0,15 & $\begin{array}{l}\text { Relación entre la población } \\
\text { extranjera y la población total en } \\
\text { porcentaje }\end{array}$ \\
\hline \multirow{5}{*}{ 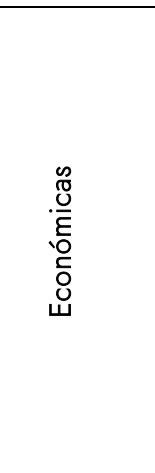 } & ValorCAT & 0,08 & 9,23 & 1,03 & 0,87 & $\begin{array}{l}\text { Cociente entre el valor de las } \\
\text { parcelas en miles de euros y el } \\
\text { número de personas registradas } \\
\text { en el Catastro. }\end{array}$ \\
\hline & GanBov & 4,85 & 25032,06 & 3050,26 & 4501,22 & $\begin{array}{l}\text { Número de cabezas de ganado } \\
\text { vacuno. }\end{array}$ \\
\hline & RBruHab & 5915,88 & 18777,41 & 10368,81 & 1722,46 & Renta bruta per cápita. \\
\hline & DeudaHab & 0 & 0,81 & 0,19 & 0,17 & $\begin{array}{l}\text { Cociente entre el saldo de la } \\
\text { deuda que los ayuntamientos } \\
\text { han contraído con el banco en } \\
\text { euros y el número de habitantes. }\end{array}$ \\
\hline & $\mathrm{PIB}$ & 2680,62 & 7168155,94 & $\begin{array}{c}176090,1 \\
0 \\
\end{array}$ & 616411,74 & $\begin{array}{l}\text { Producto interior bruto en miles } \\
\text { de euros. }\end{array}$ \\
\hline
\end{tabular}

Fuente: elaboración propia a partir del BDN 


\subsection{Procesado de datos}

Con la información que obtenida y una vez ordenada la base de datos, se realizaron tres análisis, descritos a continuación:

1. Para el análisis espacial y temporal de las Hectáreas quemadas y su correspondiente Ratio (hectáreas $/ \mathrm{n}^{\circ}$ de incendios) se llevó a cabo un análisis descriptivo de los principales estadísticos de dichas variables, comparando el comportamiento por provincia, mediante un ANOVA de un Factor, e identificando qué municipios presentaban los valores máximos y mínimos para dichas variables. Asimismo, se realizó un análisis de la tendencia durante los quince años de estudio.

2. Para determinar la relación bidimensional entre las variables independientes y las dos dependientes, se utilizaron las 314 observaciones correspondientes a cada uno de los municipios con los 15 años agregados. Habida cuenta de la falta de normalidad de las variables analizadas (Kolmogorov-Smirnov, pvalor =0,000), en lugar de usar el coeficiente de correlación de Pearson se hizo uso del coeficiente de correlación no paramétrico de Spearman.

3. Por último, para establecer la relación, multidimensionalmente, entre los aspectos socioeconómicos y ambientales que reflejan la realidad de los municipios gallegos y las Hectáreas quemadas y el Ratio hectáreas $/ n^{\circ}$ de incendios ocurridos desde 2001 a 2015, se emplearon dos modelos de regresión lineal múltiple, estimados por el método de mínimos cuadrados ordinarios. Para evitar recorridos muy grandes, asimetrías positivas o variaciones marginales no constantes, se efectuaron diferentes transformaciones (logaritmos, ratios de variables, etc.) haciendo así los datos más representativos y comparables.

Los análisis estadísticos se realizaron con los programas estadísticos informáticos IBM SPSS Statistics versión 24 y GRETL 2019.

\section{Resultados}

\subsection{Distribución espacial y temporal de los incendios forestales en Galicia}

Tal y como se ha reseñado en el apartado de metodología, la unidad de observación objeto de análisis es el municipio. Se analizan las Hectáreas quemadas y el ratio hectáreas $/ \mathrm{n}^{\circ}$ de incendios para cada uno de los quince años comprendidos entre el 2001 y el 2015.

En Galicia hay 314 municipios (concellos), siendo el municipio la administración básica más próxima al ciudadano. De ellos 93 pertenecen a la provincia de A Coruña, 67 a la de Lugo, 92 
a la de Ourense, y 62 a Pontevedra. Con respecto al resto de los municipios de España, los gallegos son grandes en extensión y especialmente en población, pues sólo 32 (el 9,8%) tienen menos de 1.000 habitantes (conforme al censo del 2018). Consecuentemente, la densidad de población de Galicia es mayor que la media de España, especialmente en la costa occidental $(\mathrm{INE}, 2019)^{5}$.

Centrando el estudio ya en los incendios ocurridos en los municipios gallegos, en la tabla 2 aparecen reflejados los estadísticos principales de las dos variables mencionadas, esto es, las Hectáreas quemadas y el ratio hectáreas $/ n^{\circ}$ de incendios durante los quince años señalados.

Los incendios forestales en Galicia tienen una marcada estacionalidad. Entre los años 2001 y 2015 se concentran en la época estival, teniendo un repunte entre los meses de febrero y abril, en los que es habitual la limpieza de terrenos y la quema de rastrojo (Braña, 2015). En este sentido, el número medio de hectáreas quemadas por municipio durante los quince años analizados ha sido de 1197,1, con una mediana de 612,1 y una desviación típica de 1553,9.

La localización de los incendios en los 15 años seleccionados también es bastante constante. La provincia de Ourense es la más afectada por los incendios forestales en donde se quema sobre todo matorral frente a superficie arbolada (PLADIGA, 2018). El valor medio más elevado en hectáreas quemadas se produce en los municipios de la provincia de Ourense, con 1.807,6, seguida por Pontevedra, con una media 1387,5, A Coruña, con 880,2 y Lugo, con 622,5. En concreto, los municipios con mayor número de hectáreas quemadas a lo largo de estos quince años han sido Manzaneda y Viana do Bolo, en Ourense, con 10 607,0 y 8320,5 hectáreas respectivamente, seguidos por Cerdedo, en Pontevedra, con 8206,2. En un intento de perfilar las causas de la concentración de incendios en un lugar u otro se observa que los lugares más afectados poseen las mayores extensiones de monte de toda Galicia. Además, la mayor parte del terreno forestal está compuesta de montes de titularidad pública, algunos de ellos declarados de utilidad pública, y montes vecinales en mano común (PLADIGA, 2018). Por otra parte, los municipios con menor número de hectáreas quemadas durante estos quince años han sido Mugardos en A Coruña, con 3,3 hectáreas, Barreiros en Lugo, con 4,4, y Cabanas en Lugo con 4,3. Estos municipios tienen los siguientes aspectos en común: en primer lugar, todos se encuentran en las provincias del norte de Galicia; en segundo lugar, disponen de menos hectáreas forestales en comparación con los municipios más afectados; y por último, la provincia

5 Ver

http://www.ine.es/dyngs/INEbase/es/operacion.htm?c=Estadistica_C\&cid=1254736177011\&menu=resultado $\underline{s \& i d p=1254734710990}$ 
de Lugo cuenta con la mayor superficie forestal gestionada para productos madereros (PLADIGA, 2018).

No obstante, las pequeñas diferencias biogeográficas que puedan existir entre todos los municipios antes mencionados no son un aspecto clave a la hora de explicar las diferencias que existen entre estos mismos municipios con respecto a los incendios forestales (Rodríguez \& Ramil-Rego, 2007).

Si se analiza la Intensidad o distribución de hectáreas por número de incendios, se observa que el ratio medio obtenido en Galicia durante los quince años analizados ha sido de 4,3 hectáreas por incendio, con una mediana de 2,8 y una desviación típica de 5,1. Los municipios de Ourense y Pontevedra son los que presentan dicho ratio medio más alto, con 4,7 y 4,6 respectivamente, seguidos por A Coruña y Lugo con 4,0 y 3,8 respectivamente. El distrito ${ }^{6}$ de Verín-Viana y el de Valdeorras-Trives, ambos en la provincia de Ourense, ocupan los lugares uno y dos respectivamente (IGE, 2013). El municipio donde el ratio alcanza un valor más elevado a lo largo de estos quince años ha sido en Cerdedo $(37,5)$, en Pontevedra, seguido por Ribeira de Piguín (32,3), en Lugo, y A capela $(30,2)$ en A Coruña. Por el contrario, los municipios donde menor ratio ha habido durante estos quince años han sido Cambados $(0,15)$ en Pontevedra, Mugardos $(0,15)$ en A Coruña y Barreiros $(0,18)$ en Lugo.

La tendencia de concentración de los incendios forestales en el interior de Galicia se rompió en el año 2006. El fuego pasó de zonas rurales a las más pobladas y del interior a la costa. El cambio de situación de los incendios y su proximidad a los centros de población colapsaron los servicios de extinción provocando la alerta social y una imagen caótica en Galicia (Barreal et al., 2012; Balsa \& Hermosilla, 2013). En este sentido, y con el objeto de determinar si el comportamiento era el mismo entre las cuatro provincias, se efectuó un contraste de igualdad de medias (Anova de un Factor) para las dos variables. Así, se obtuvieron dos patrones de comportamiento diferente para el las Hectáreas quemadas y la Intensidad, encontrándose por un lado las provincias de Ourense y Pontevedra, con un comportamiento similar, sin diferencias significativas, y por otro las provincias de A Coruña y Lugo, donde las hectáreas quemadas son significativamente inferiores a las provincias del sur. Sin embargo, no se encontraron diferencias

6 El gobierno regional, la Xunta de Galicia estableció a partir del año 1999 el distrito forestal como herramienta de gestión. El distrito se define como "unidad administrativa básica de planificación de la defensa contra incendios forestales de Galicia, dotada de recursos propios y con capacidad de planificación. Cada distrito está compuesto por la agrupación de municipios pertenecientes todos a una misma provincia" (IGE, 2013). 
significativas ( $\mathrm{p}$-valor) en cuanto al Ratio hectáreas $/ \mathrm{n}^{\circ}$ de incendios. Estos resultados se muestran en la Tabla 2.

Tabla 2. Estadísticos y frecuencias mayores y menores de hectáreas quemadas y ratio hectáreas $/ n^{\circ}$ incendios

\begin{tabular}{|c|c|c|c|c|c|c|c|}
\hline Variables & Estadísticos & Total & A Coruña & Lugo & Ourense & Pontevedra & p-valor \\
\hline \multirow{6}{*}{$\begin{array}{l}\text { Hectáreas } \\
\text { quemadas }\end{array}$} & Media & 1197,08 & 880,19 & 622,49 & 1807,57 & 1387,5 & \multirow{6}{*}{0,000} \\
\hline & D.T. & 1553,93 & 1038,27 & 892,8 & 2053,29 & 1580,42 & \\
\hline & Mediana & 612,1 & 443,74 & 333,94 & 1282,78 & 658,18 & \\
\hline & Mínimo & 3,37 & 3,37 & 4,46 & 8,53 & 16,71 & \\
\hline & Máximo & 10607,0 & 4430,07 & 5813,86 & 10607,01 & 8206,2 & \\
\hline & Asimetría & 2,53 & 1,59 & 3,52 & 2,10 & 1,77 & \\
\hline \multirow{10}{*}{ Municipios } & \multirow{5}{*}{\multicolumn{2}{|c|}{ Mayor }} & $\begin{array}{c}\text { Carnota } \\
(4.430,07)\end{array}$ & $\begin{array}{c}\text { Quiroga } \\
(5.813,86)\end{array}$ & $\begin{array}{c}\text { Manzaned } \\
a \\
(10.607,01 \\
)\end{array}$ & $\begin{array}{r}\text { Cerdedo } \\
(8.206,2)\end{array}$ & \\
\hline & & & $\begin{array}{c}\text { Lousame } \\
(3.918,33)\end{array}$ & $\begin{array}{c}\text { Navia de } \\
\text { Suarna } \\
(2.589,45)\end{array}$ & $\begin{array}{l}\text { Viana do } \\
\text { Bolo } \\
(8.320,55)\end{array}$ & $\begin{array}{l}\text { Pazos de } \\
\text { Borbén } \\
(5.287,12)\end{array}$ & \\
\hline & & & $\begin{array}{c}\text { Muxía } \\
(3.621,15)\end{array}$ & $\begin{array}{l}\text { Cervantes } \\
(2.327,9)\end{array}$ & $\begin{array}{c}\text { Cualedro } \\
(8.295,56)\end{array}$ & $\begin{array}{c}\text { Cañiza, A } \\
(3.808,47) \\
\end{array}$ & \\
\hline & & & $\begin{array}{c}\text { Mazaricos } \\
(3.532,43)\end{array}$ & $\begin{array}{l}\text { Saviñao, O } \\
(2.177,89)\end{array}$ & $\begin{array}{c}\text { Carballeda } \\
\text { de } \\
\text { Valdeorras } \\
(6.797,34)\end{array}$ & $\begin{array}{c}\text { Ponte } \\
\text { Caldelas } \\
(3.800,34)\end{array}$ & \\
\hline & & & $\begin{array}{c}\text { Negreira } \\
(3.504,23)\end{array}$ & $\begin{array}{c}\text { Palas de } \\
\text { Rei } \\
(2.159,99)\end{array}$ & $\begin{array}{c}\text { Laza } \\
(6.422,35)\end{array}$ & $\begin{array}{c}\text { Forcarei } \\
(3.694,03)\end{array}$ & \\
\hline & \multirow{5}{*}{\multicolumn{2}{|c|}{ Menor }} & $\begin{array}{c}\text { Mugardos } \\
(3,37)\end{array}$ & $\begin{array}{c}\text { Barreiros } \\
(4,46)\end{array}$ & $\begin{array}{l}\text { Beade } \\
(8,53)\end{array}$ & Bueu $(16,71)$ & \\
\hline & & & $\begin{array}{c}\text { Cabanas } \\
(4,34)\end{array}$ & Alfoz $(8,28)$ & $\begin{array}{c}\text { Pontedeva } \\
(18,93)\end{array}$ & $\begin{array}{c}\text { Mondariz- } \\
\text { Balneario } \\
(32,06)\end{array}$ & \\
\hline & & & $\begin{array}{l}\text { Cariño } \\
(8,08)\end{array}$ & $\begin{array}{c}\text { Rábade } \\
(8,58)\end{array}$ & $\begin{array}{c}\text { Arnoia, A } \\
(58,46)\end{array}$ & $\begin{array}{c}\text { Cambados } \\
(34,22\end{array}$ & \\
\hline & & & $\begin{array}{c}\text { Miño } \\
(14,14)\end{array}$ & $\begin{array}{c}\text { Lourenzá } \\
(17,77)\end{array}$ & $\begin{array}{c}\text { Leiro } \\
(93,44)\end{array}$ & $\begin{array}{c}\text { Ribadumia } \\
(34,99)\end{array}$ & \\
\hline & & & $\begin{array}{c}\text { Bergondo } \\
(15,5)\end{array}$ & $\begin{array}{l}\text { Burela } \\
(23,83)\end{array}$ & $\begin{array}{c}\text { Rúa, A } \\
(103,31)\end{array}$ & $\begin{array}{c}\text { Illa de } \\
\text { Arousa, A } \\
(41,85)\end{array}$ & \\
\hline \multirow{6}{*}{$\begin{array}{c}\text { Ratio } \\
\text { hectáreas } / \mathrm{n}^{\circ} \\
\text { incendios } \\
\text { (Intensidad) }\end{array}$} & Media & 4,28 & 3,99 & 3,83 & 4,71 & 4,58 & \multirow{6}{*}{0,639} \\
\hline & D.T. & 5,07 & 5,18 & 4,97 & 3,21 & 6,97 & \\
\hline & Mediana & 2,76 & 2,18 & 2,26 & 3,85 & 1,94 & \\
\hline & Mínimo & 0,15 & 0,15 & 0,18 & 0,20 & 0,15 & \\
\hline & Máximo & 37,47 & 30,22 & 32,29 & 18,35 & 37,47 & \\
\hline & Asimetría & 3,05 & 3,07 & 3,63 & 1,62 & 2,63 & \\
\hline
\end{tabular}


Tabla 2. Continuación

\begin{tabular}{|c|c|c|c|c|c|c|}
\hline Variables & Estadísticos & Total & A Coruña & Lugo & Ourense & $\begin{array}{c}\text { Ponteve } \\
\text { dra }\end{array}$ \\
\hline \multirow{10}{*}{ Municipios } & \multirow{5}{*}{ Mayor } & $\begin{array}{c}\text { Capela, A } \\
(30,22)\end{array}$ & $\begin{array}{c}\text { Ribeira de } \\
\text { Piquín } \\
(32,29)\end{array}$ & $\begin{array}{c}\text { Laza } \\
(18,35)\end{array}$ & $\begin{array}{c}\text { Cerdedo } \\
(37,47)\end{array}$ & \\
\hline & & $\begin{array}{c}\text { Camariñas } \\
(26,7)\end{array}$ & $\begin{array}{l}\text { Quiroga } \\
(19,06)\end{array}$ & $\begin{array}{l}\text { Avión } \\
(14,86)\end{array}$ & $\begin{array}{c}\text { Pazos de } \\
\text { Borbén } \\
(22,5)\end{array}$ & \\
\hline & & $\begin{array}{c}\text { Carnota } \\
(21,2)\end{array}$ & $\begin{array}{c}\text { Trabada } \\
(13,83)\end{array}$ & $\begin{array}{c}\text { Larouco } \\
(13,99)\end{array}$ & $\begin{array}{l}\text { Campo } \\
\text { Lameiro } \\
(20,49)\end{array}$ & \\
\hline & & $\begin{array}{l}\text { Padrón } \\
(17,48)\end{array}$ & $\begin{array}{l}\text { Navia de } \\
\text { Suarna } \\
(13,56)\end{array}$ & $\begin{array}{c}\text { Carballeda } \\
\text { de } \\
\text { Valdeorras } \\
(11,2)\end{array}$ & Oia $(19,28)$ & \\
\hline & & $\begin{array}{c}\text { Cee } \\
(13,06)\end{array}$ & $\begin{array}{c}\text { Cervantes } \\
(11,25)\end{array}$ & $\begin{array}{c}\text { Cualedro } \\
(10,46)\end{array}$ & $\begin{array}{c}\text { Pontecesures } \\
(17,63)\end{array}$ & \\
\hline & \multirow{5}{*}{ Menor } & $\begin{array}{c}\text { Mugardos } \\
(0,15)\end{array}$ & $\begin{array}{c}\text { Barreiros } \\
(0,18)\end{array}$ & Beade $(0,2)$ & $\begin{array}{c}\text { Cambados } \\
(0,15)\end{array}$ & \\
\hline & & $\begin{array}{c}\text { Cabanas } \\
(0,18)\end{array}$ & $\begin{array}{l}\text { Rábade } \\
(0,26)\end{array}$ & Leiro $(0,83)$ & Bueu $(0,17)$ & \\
\hline & & $\begin{array}{c}\text { Bergondo } \\
(0,22)\end{array}$ & $\begin{array}{l}\text { Alfoz } \\
(0,39)\end{array}$ & $\begin{array}{c}\text { San Amaro } \\
(0,92)\end{array}$ & Vigo $(0,17)$ & \\
\hline & & $\begin{array}{c}\text { Cambre } \\
(0,23)\end{array}$ & $\begin{array}{l}\text { Viveiro } \\
(0,44)\end{array}$ & $\begin{array}{c}\text { Pontedeva } \\
(0,95)\end{array}$ & $\begin{array}{l}\text { Nigrán } \\
(0,25)\end{array}$ & \\
\hline & & $\begin{array}{l}\text { Miño } \\
(0,26)\end{array}$ & $\begin{array}{c}\text { Ribadeo } \\
(0,55)\end{array}$ & $\begin{array}{c}\text { Arnoia, A } \\
(1,03)\end{array}$ & $\begin{array}{c}\text { Grove, } 0 \\
(0,35)\end{array}$ & \\
\hline
\end{tabular}

Fuente: elaboración propia a través de datos del BDN

\subsection{Análisis de tendencia}

Galicia sigue siendo la comunidad autónoma española más afectada por los incendios forestales desde comienzos del siglo XX. La Figura 1 ofrece una comparación entre Galicia y el resto de España con respecto a las Hectáreas quemadas e Intensidad, evidenciando el peso que tiene esta comunidad dentro de estas catástrofes.

Efectuado el correspondiente análisis de tendencia para las hectáreas quemadas y el ratio de ambas variables por municipio y por año, desde el 2001 al 2015 ( $n=4710$ ) en la Tabla 3, se observa una disminución significativa en las hectáreas quemadas; sin embargo, el ratio de intensidad no ofrece una tendencia significativa. 
Figura 1. Relación entre Galicia (G) y España sin Galicia (E-G). 2001-2015 (15). Ha quemadas e intensidad

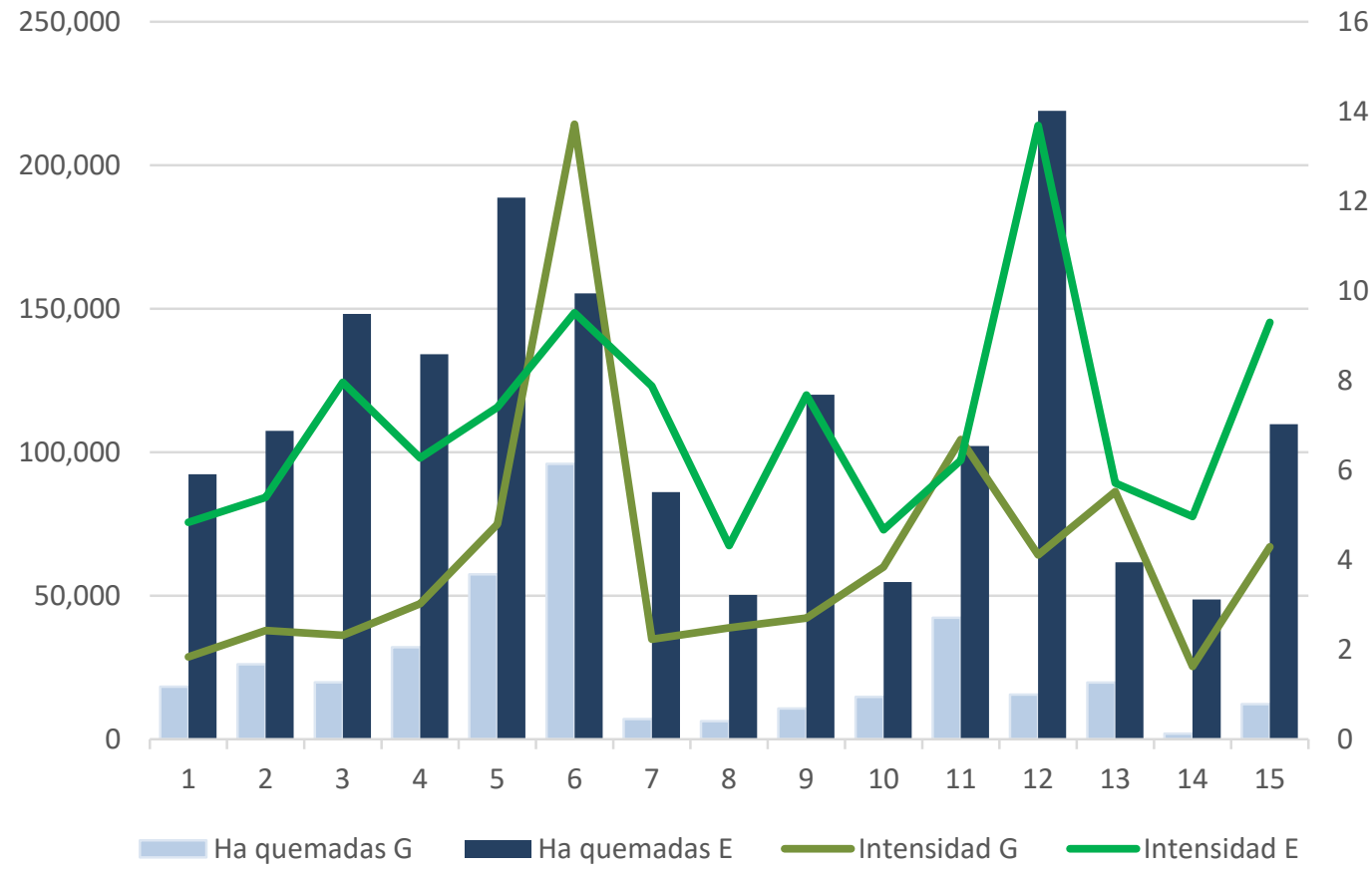

Fuente: elaboración propia a partir de los datos obtenidos del BDN

Tabla 3. Análisis de tendencia Hectáreas quemadas e Intensidad

\begin{tabular}{|c|c|c|c|}
\hline & $\begin{array}{c}\text { Variable } \\
\text { dependiente }\end{array}$ & Ha quemadas & $\begin{array}{c}\text { Ratio } \mathrm{Ha} / \mathrm{n}^{\circ} \text { incendios } \\
\text { (Intensidad) }\end{array}$ \\
\hline \multirow{3}{*}{$2001-2015$} & Cte & 10863,468 & $-103,649$ \\
\hline & año & $-5,370 * * *$ & 0,054 \\
\hline & $\mathrm{R}^{2}$ & $0,007 * * *$ & 0,000 \\
\hline \multirow{3}{*}{$2001-2006$} & Cte & $-89921,607$ & $-4412,669$ \\
\hline & año & $44,948 * * *$ & $2,205 * \star \star$ \\
\hline & $\mathrm{R}^{2}$ & $0,047 * * *$ & $0,034 * * *$ \\
\hline \multirow{3}{*}{$2007-2015$} & Cte & $-2574,172$ & $-647,956$ \\
\hline & año & 1,302 & $0,324 * *$ \\
\hline & $R^{2}$ & 0,000 & $0,002 * *$ \\
\hline
\end{tabular}

Fuente: elaboración propia a través de los datos del BDN 
No obstante, se pueden identificar dos periodos claramente diferenciados: el primero va desde el 2001 hasta el 2006 y se caracteriza por que las hectáreas quemadas medias por municipio aumentan de forma significativa. En el segundo periodo no hay una tendencia significativa. Así, desde el 2006 hasta el 2015, se produce una drástica disminución de las hectáreas medias quemadas por municipio en los años 2007 y 2008, para continuar con un repunte los años siguientes hasta el 2011; en los últimos tres años de este periodo se produce un descenso, pero en menor proporción que el que tuvo lugar en los años 2007 y 2008. En definitiva, existe un aumento significativo en el primer periodo y no significativo en el segundo.

Por su parte, si se observa el ratio separadamente en ambos periodos temporales, se ve una tendencia creciente significativa, al $1 \%$ y al 5 \% respectivamente, siendo los años más virulentos, (donde más hectáreas quemadas ha habido por incendio) el 2006 y el 2011.

\subsection{Relación de las características ambientales, territoriales y socioeconómicas con los incendios forestales}

Para determinar la posible existencia de una relación entre las variables que recogen las diferentes dimensiones ya comentadas (ambientales, territoriales, sociales y económicas) y las dos variables consideradas, esto es, Hectáreas quemadas y Ratio hectáreas $/ n^{\circ}$ de incendios se estimó el coeficiente de correlación de Spearman, cuyo valor y significatividad pueden observarse en la Tabla 4. Así, se observa una correlación significativa y positiva entre las hectáreas quemadas con las variables Índice de reemplazo, hectáreas rústicas y el Índice de estructura de población activa; y significativa y negativa con la Densidad, Proporción de población extranjera, Valor Catastral, Renta Bruta per Cápita, PIB y Núcleos diseminados. Esto pone de manifiesto que aquellos municipios donde mayor es el índice de reemplazo, donde hay un mayor número de hectáreas rusticas y donde el índice de estructura de población activa es más alto, mayor es el número de hectáreas quemadas; y donde existe una mayor densidad, una mayor proporción de población extranjera, un mayor valor catastral, una mayor renta bruta per cápita, un mayor PIB y una mayor diseminación, menor es el número de hectáreas quemadas.

Por su parte, se observa una correlación significativa positiva entre el Ratio hectáreas quemadas $/ \mathrm{n}^{\circ}$ de incendios con las variables Número de personas mayores de 64 años, Índice de reemplazo, Índice de estructura de población activa y Número de hectáreas rusticas; y correlación significativa negativa con la Densidad, Proporción de población extranjera, Renta bruta per cápita, PIB y Núcleos diseminados. Por lo que, con una población envejecida, un mayor índice de reemplazo, una mayor estructura de población activa y un mayor número de hectáreas rusticas, existe una más alta intensidad de los incendios forestales; y a mayor 
proporción de población extranjera, mayor renta bruta, mayor PIB y mayor diseminación, la intensidad de dichos incendios es menor.

No se observa relación significativa con las variables climáticas, posiblemente debido al agregado de 15 años realizado, y la consecuente falta de variabilidad en dichas variables.

Según lo anterior, y a partir de la realización de un análisis de dependencia bidimensional, parece que existe una relación significativa entre, al menos, alguna de las variables de las dimensiones territoriales, sociales y económicas y las Hectáreas quemadas, así como también con la Intensidad fruto de los incendios forestales acaecidos en los municipios gallegos entre el año 2001 y 2015. Por lo tanto, los incendios forestales acaecidos en Galicia están vinculados o relacionados con variables de carácter socioeconómico.

No obstante, es bien sabido que en la ocurrencia de los incendios forestales suelen incidir varios factores simultáneamente, presentando un marcado carácter multidimensional. Es por ello, que en el siguiente apartado se va a tratar de explicar la ocurrencia de dichos incendios considerando, ahora, conjuntamente las variables en las diferentes dimensiones ya comentadas.

\subsection{Modelo de regresión lineal múltiple}

La especificación de los modelos para explicar la incidencia de las variables seleccionadas en las diferentes dimensiones sobre las hectáreas quemadas y el ratio hectáreas $/ \mathrm{n}^{\circ}$ de incendios $\mathrm{O}$ Intensidad en los municipios de Galicia entre 2001-2015 ha sido la siguiente:

$$
Y=\beta_{0}+\beta_{1} X_{1}+\ldots+\beta_{k} X_{k}+\varepsilon
$$

Variables dependientes

$Y=$ Hectáreas quemadas;

$Y=$ Intensidad (ratio hectáreas $/ n^{\circ}$ de incendios)

Variables explicativas

$X=$ Variables utilizadas $^{7}$

$k=$ Número de variables

Parámetros de la ecuación

$\beta_{0}=$ Término independiente. Magnitud media para todos los sujetos

$\beta=$ Medida del impacto de cada una de las variables dentro de la ecuación de regresión Perturbación aleatoria

$\varepsilon$ Perturbación aleatoria

7 X1 = Ln Población>64 + X2LnDensidad + X3Lnl.Remplazo + X4I.Masculinidad + X5I.RecACT + X6LnPoblaciónEXT + X7LnValorCAT + X8 LnGanBov + X9 LnRBruHab + X10LnDeudaHab + X11LnPIB+X12LnDisNucleos + X13LnGanaderías + X14LnHaRústicas + X15MediaTaEST + X16MediaHaEST + X17MediaVoEST 
Para determinar si existían diferencias según las provincias se realizó el test de Chow (Fisher, 1970) entre la región norte (A Coruña y Lugo) y la región sur (Ourense y Pontevedra) y el mismo test dentro de cada área para comparar cada par de provincias. Así, para la variable Hectáreas quemadas se observa un comportamiento diferenciado para las cuatro provincias, y para el ratio hectáreas $/ \mathrm{n}^{\circ}$ de incendios se observan diferencias estructurales entre el norte y el sur, y dentro del sur entre las provincias de Pontevedra y Ourense, y no así entre A Coruña y Lugo.

El modelo se llevó a cabo, por lo tanto, para todos los municipios del territorio gallego (total) y posteriormente en los municipios de cada provincia por separado, en función de los resultados del análisis estructural efectuado.

Por otra parte, para solucionar la cuestión de la heterocedasticidad que se presentaba en el modelo se utilizaron desviaciones tipicas robustas. Asimismo, para contrarrestar los problemas ocasionados por las variables con gran rango de variación y/o asimetría a la derecha, o los efectos marginales no constantes fueron tomados logaritmos en los casos necesarios, como ya se ha comentado con anterioridad.

En la Tabla 4 se muestran los nueve modelos finales utilizados para explicar las dos variables dependientes consideradas: dos modelos para todo el conjunto de municipios gallegos (total, uno por cada variable dependiente), cuatro para la variable Hectáreas quemadas (uno por cada una de las cuatro provincias) y otros tres para la variable Intensidad (uno para el norte y otros dos para cada una de las provincias del sur de Galicia). 
Tabla 4. Coeficiente de correlación de Spearman, modelos de regresión lineal múltiple

\begin{tabular}{|c|c|c|c|c|c|c|c|c|c|c|c|c|}
\hline \multirow{2}{*}{\multicolumn{2}{|c|}{ Variables }} & \multicolumn{6}{|c|}{ Ha Quemadas } & \multicolumn{5}{|c|}{ Intensidad (PropHalNC) } \\
\hline & & \multirow{3}{*}{$\begin{array}{c}\text { Rho de } \\
\text { Spearman }\end{array}$} & Total & A Coruña & Lugo & Ourense & Pontevedra & \multirow{3}{*}{$\begin{array}{c}\text { Rho de } \\
\text { Spearman }\end{array}$} & Total & Norte & Ourense & Pontevedra \\
\hline \multirow[t]{2}{*}{ Dimensiones } & \begin{tabular}{c|} 
Variable \\
Independiente
\end{tabular} & & $b$ & $b$ & $b$ & $b$ & $b$ & & $b$ & $b$ & $b$ & $b$ \\
\hline & const & & 34475,5 & 43163,1 & $-3008,16$ & 25563,7 & $-20713,7$ & & 86,88 & 73,61 & 54,15 & 123,02 \\
\hline \multirow{6}{*}{ POBLACIONAL } & LnPoblación>64 & 0,01 & 516,04 & $745,47 *$ & 1029,28 ** & 731,58 & $-434,75$ & $-0,29 * *$ & 0,43 & 0,82 & $-0,08$ & $-5,85^{* *}$ \\
\hline & LnDensidad & $-0,30 * *$ & $-815,68 * * *$ & $-126,45$ & $-794,09 *$ & 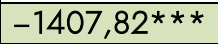 & 167,30 & $-0,41 * *$ & $-1,37$ & $-1,26$ & $-0,81$ & 2,07 \\
\hline & Lnl.Remplazo & $0,19 * *$ & $-3045,47 * \star * *$ & $-4627,59 * \star *$ & $-2148,76$ & $-3913,79 *$ & $-4919,60 *$ & $0,31 * *$ & $-9,72 * *$ & $-17,06 * *$ & $-3,21$ & $-20,80$ \\
\hline & I.Masculinidad & $-0,01$ & 9,53 & $-19,71$ & 10,51 & 43,76 & $-83,07$ & 0,04 & $-0,06$ & $-0,00$ & $-0,05$ & $-0,32$ \\
\hline & I.RecACT & $0,19 * *$ & 0,39 & 0,87 & 4,47 & $-0,03$ & $31,13 * *$ & $0,31 * *$ & 0,00 & 0,02 & 0,00 & 0,14 \\
\hline & LnPoblaciónEXT & $-0,21 * *$ & $-133,96$ & $-90,47$ & $-81,17$ & $-148,92$ & $-385,48$ & $-0,34$ ** & $-0,80$ & $-0,26$ & $-0,79$ & $-2,41^{*}$ \\
\hline \multirow[t]{5}{*}{ ECONOMICA } & LnValorCAT & $-0,11^{*}$ & $-195,78$ & $-304,08 *$ & 264,56 & $-408,62^{\star}$ & $742,25 *$ & $-0,06$ & 0,56 & $-0,70$ & $-0,83^{*}$ & 4,12 ** \\
\hline & LnGanBov & 0,04 & $-11,24$ & 371,06 & $-50,90$ & 268,22 & 104,33 & $-0,02$ & $-0,69 * *$ & $-0,05$ & 0,41 & $-0,69$ \\
\hline & LnRBruHab & $-0,41$ ** & $-2884,11$ *** & $-2311,25$ ** & 174,95 & $-1017,47$ & 477,17 & $-0,40$ ** & $-3,40$ & $-3,23$ & $-0,76$ & 6,51 \\
\hline & LnDeudaHab & 0,02 & $-219,18$ & $-371,88$ & 1157,50 & $-748,51$ & 113,28 & $-0,05$ & $-0,38$ & $-0,93$ & 0,30 & $-1,14$ \\
\hline & $\mathrm{LnPIB}$ & $-0,09$ & 389,20 & $-349,76$ & $-120,20$ & 472,91 & 550,86 & $-0,34 * *$ & 0,08 & $-0,53$ & 0,60 & 3,65 \\
\hline \multirow[t]{3}{*}{ TERRITORIAL } & LnDisNucleos & $-0,24 * *$ & $-220,62 * * *$ & $-42,27$ & $-90,99$ & $-32,021$ & 94,47 & $-0,20 * *$ & $-0,25$ & $-0,38$ & $-0,10$ & $-0,33$ \\
\hline & LnGanaderías & $-0,23 * \star$ & $-331,41 * \star$ & $-1347,08 * *$ & $-594,55$ & $-401,42$ & $-781,13 * *$ & $-0,34 * *$ & $-0,49$ & $-3,24^{*}$ & $-1,27^{*}$ & $-2,16$ \\
\hline & LnHaRústicas & $0,24 * *$ & 287,96 & 2637,15 ** & $-5048,10$ & $2587,31^{*}$ & 839,73 & $0,32 * *$ & 1,15 & $10,81^{\star}$ & $6,14 * * *$ & $-0,97$ \\
\hline \multirow[t]{5}{*}{ METEOROLOGICA } & MediaTaEST & 0,00 & $-90,68$ & $-216,11$ & $-3,16$ & $-431,25$ & 1108,77 & $-0,00$ & $-0,32$ & 0,33 & $-1,13$ & $-2,44$ \\
\hline & MediaHaEST & $-0,00$ & $-23,03$ & $-33,55$ & 7,71 & $-60,11$ & 293,34 & 0,00 & 0,01 & 0,21 & $-0,25 * \star$ & 0,02 \\
\hline & MediaVoEST & 0,00 & 14,72 & 40,18 & 76,42 & $-377,92$ & $-1788,39$ & 0,01 & 0,37 & 0,45 & 0,09 & $-6,07$ \\
\hline & R2 & & 0,37 & 0,49 & 0,59 & 0,54 & 0,63 & & 0,16 & 0,26 & 0,33 & 0,52 \\
\hline & $n$ & & 314 & 93 & 67 & 92 & 62 & & 314 & 160 & 92 & 62 \\
\hline \multicolumn{2}{|c|}{ Contraste de Chow Norte/Sur } & \multicolumn{6}{|c|}{ Chi-cuadrado $(18)=62,33$ con valor $p 0,000$ forma $F: F(18,278)=3,46$ con valor $p 0,000$} & \multicolumn{5}{|c|}{$\begin{array}{l}\text { Chi-cuadrado }(18)=32,86 \text { con valor } p 0,017 \text { forma } F: F(18,278)=1,82 \text { con valor } p \\
0,022\end{array}$} \\
\hline \multicolumn{2}{|c|}{ Contraste de Chow Este/Oeste } & \multicolumn{6}{|c|}{ Chi-cuadrado $(18)=65,07$ con valor $p 0,00$ forma $F: F(18,278)=3,61$ con valor $p 0,000$} & \multirow{2}{*}{\multicolumn{5}{|c|}{$\begin{array}{l}\text { Chi-cuadrado }(18)=37,84 \text { con valor } p 0,004 \mathrm{~F}(18,278)=2,10 \text { con valor } \mathrm{p} 0,006 \\
\text { Chi-cuadrado }(18)=22,12 \text { con valor } \mathrm{p} 0,226 \text { forma } \mathrm{F}: \mathrm{F}(18,124)=1,22 \text { con valor } \mathrm{p} \\
0,248\end{array}$}} \\
\hline \multicolumn{2}{|c|}{ Contraste de Chow Norte (A Coruña-Lugo) } & \multicolumn{6}{|c|}{ Chi-cuadrado $(18)=37,57$ con valor p 0,004 forma $F: F(18,124)=2,08$ con valor $p 0,009$} & & & & & \\
\hline \multicolumn{2}{|c|}{ Contraste de Chow Sur (Ourense-Pontevedra) } & \multicolumn{6}{|c|}{ Chi-cuadrado $(18)=47,92$ con valor $p 0,000$ forma $F: F(18,118)=2,66$ con valor $p 0,000$} & \multicolumn{5}{|c|}{ 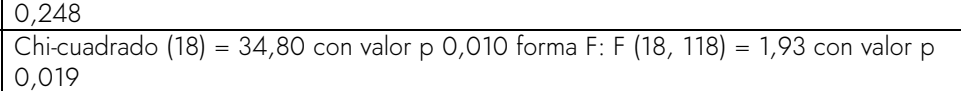 } \\
\hline \multirow{2}{*}{\multicolumn{2}{|c|}{$\begin{array}{l}\text { Contraste de Chow Este (Ourense-Lugo) } \\
\text { Contraste de Chow Oeste (A Coruña- } \\
\text { Pontevedra) }\end{array}$}} & \multicolumn{6}{|c|}{ Chi-cuadrado $(18)=39,49$ con valor $p 0,002 \mathrm{~F}(18,123)=2,19$ con valor $\mathrm{p} 0,006$} & \multicolumn{5}{|c|}{ Chi-cuadrado $(18)=29,11$ con valor $p 0,047 \mathrm{~F}(18,123)=1,61$ con valor $\mathrm{p} 0,065$} \\
\hline & & Chi-cuadrado & $(18)=57,96$ con va & lor p $0,000 \mathrm{~F}(18,11$ & 19) $=3,22 \mathrm{con} v$ & lor $p 0,000$ & & \multicolumn{5}{|c|}{ Chi-cuadrado $(18)=25,59$ con valor $p 0,109 F(18,119)=1,42$ con valor $p 0,133$} \\
\hline
\end{tabular}

Fuente: elaboración propia 
La $R^{2}$ que presentan los modelos se pueden considerar representativa ya que se logra una capacidad predictiva alta de las variables dependientes en todos los modelos, oscilando entre el 16,7\% para el modelo Total explicando la variable hectáreas $/ \mathrm{n}^{\circ}$ incendios hasta el 63,8 \% en el modelo para Pontevedra explicando las Hectáreas quemadas. Por lo tanto, la incidencia de los incendios forestales en Galicia tiene una alta relación con las variables socioeconómicas y territoriales que caracterizan a los municipios de esta comunidad, al resultar los modelos estimados significativos conjuntamente.

a) Variable dependiente: Hectáreas quemadas

En el modelo Total, las variables que resultan significativas al 1\% son Densidad, Índice de reemplazo, Renta bruła por habitante y Núcleos diseminados. Ninguna de las variables climáticas resulta significativa.

Al no haber estabilidad estructural entre las cuatro provincias se ha realizado una estimación del modelo para cada una de las mismas. Así, en A Coruña han resultado significativas al 1 \% Índice de reemplazo", al 5 \% renta bruta por habitante, Número de granjas ganaderas y Número de hectáreas rusticas, y al 10 \% Población mayor de 64 años y Valor catastral". En Lugo han resultado significativas, al 5 \% Población mayor de 64 años y al 10 \% Densidad. En Ourense las variables significativas han sido, al 1 \% Densidad y al 10 \% Índice de reemplazo, Valor catastral y Número de hectáreas rusticas. Y, finalmente, en Pontevedra, las variables significativas resultantes al $5 \%$ han sido el Índice de estructura de población activa y Número de granjas ganaderas y al $10 \%$ el Índice de reemplazo y el valor catastral.

b) Variable dependiente: ratio hectáreas $/ n^{\circ}$ de incendios (intensidad)

En el modelo total, las únicas variables que resultan significativas al $5 \%$ son el índice de reemplazo y el número de cabezas de ganado bovino.

En el modelo norte, la única variable que resulta significativa al $5 \%$ es el índice de reemplazo, y al 10 \% el Número de granjas ganaderas y el Número de hectáreas rusticas.

En el sur, al no haber estabilidad estructural se han estimado dos modelos, uno por provincia. Así en Ourense, resulta significativa al $1 \%$ el Número de hectáreas rústicas, al 5 \% la Humedad relativa y al $10 \%$ el Valor catastral y el Número de granjas ganaderas. Por su parte en Pontevedra, las variables significativas al $5 \%$ ha sido Población mayor de 64 años y Valor catastral y al 10 \% Proporción de población extranjera. 
Si nos fijamos en el signo que tienen los coeficientes $(\beta)$, las relaciones, directa o inversa, con las variables dependientes, esto es, Hectáreas quemadas o Ratio hectáreas $/ \mathrm{n}^{\circ}$ de incendios coinciden en todos los modelos para casi todas las variables y se explican de la siguiente manera:

- La relación es inversa en el caso de la Densidad, Índice de reemplazo, Renta bruta por habitante, Número de granjas ganaderas y Número de cabezas de bovino, lo que indica que, a menor valor de estas variables, mayor incidencia en las Hectáreas quemadas o en el grado de Intensidad de los incendios medido a través del Ratio hectáreas $/ \mathrm{n}^{\circ}$ de incendios hay. Así, la mayor densidad de población, el mayor índice de reemplazo, la mayor renta por habitante y el mayor número de ganaderías son factores de protección para los municipios ante la incidencia de los incendios forestales. Con relación a las variables meteorológicas, la única que resulta significativa e inversa es Humedad relativa, en Ourense; ello supone una mayor incidencia de incendios cuanto menor sea la humedad, como es lógico.

- La relación es directa para Hectáreas rústicas, esto es, a mayor cantidad de hectáreas rústicas mayor incidencia de los incendios forestales, siendo este un claro factor de riesgo. También se detecta una relación directa en el caso de Índice de estructura de población activa (porcentaje de personas mayores en edad de trabajar respecto al porcentaje de jóvenes): cuanto más alto es este índice, mayor es la incidencia en la ocurrencia de incendios; esto puede estar vinculado, al envejecimiento de la población.

- El resto de las variables presentan una relación bien directa o bien inversa dependiendo del modelo especificado. Así, Población mayor de 64 años tiene un impacto directo en las hectáreas quemadas en A Coruña y Lugo, mientras que dicho impacto es inverso sobre la Intensidad de los incendios en la provincia de Pontevedra. Valor catastral presenta un impacto negativo sobre las hectáreas quemadas en A Coruña y Ourense y positivo en Pontevedra, y negativo también sobre la Intensidad en Ourense y positivo en Pontevedra. En el caso concreto del valor catastral, una puntuación más baja implica que las parcelas tienen un menor valor, y por lo tanto se descuidan las labores de gestión y cuidado, favoreciendo las Hectáreas quemadas y/o la Intensidad cuando tiene lugar algún incendio forestal.

- Por su parte Proporción de extranjeros presenta un signo negativo y significativo sólo cuando se trata de explicar la Intensidad de los incendios y sólo en Pontevedra, lo que implicaría que, a mayor porcentaje de extranjeros, menor Intensidad de los incendios en los municipios gallegos. En todo caso, debe reseñarse que el porcentaje de extranjeros en Galicia es bajo, suponiendo en 2019, el 3,7 \% de la población según el INE. Además, entre 2010 y 2017, el 
número de ayuntamientos gallegos cuya población extranjera supera el $5 \%$ del total se ha reducido casi a la mitad, pasando de 36 en 2010 a 20 a finales de 2017 (Rodríguez, 2018, October 29).

Con los datos obtenidos se puede observar primeramente una clara diferencia entre el norte y el sur en general y entre las provincias en particular. Por lo tanto, los requerimientos para mitigar los efectos de las variables socioeconómicas sobre las características de los incendios son diferentes dependiendo de dónde nos situemos.

Dentro de las variables poblacionales y sociales destaca el envejecimiento de la población como causa del aumento de las Hectáreas quemadas y la Intensidad. También destaca la densidad: donde esta es menor, se producen más incendios debido a un abandono del territorio. Las dos variables en conjunto reflejan que zonas deprimidas, con índices que envejecimiento alto, presentan más Hectáreas quemadas y una mayor Intensidad. Además, se produce una reducción del valor catastral que conlleva un abandono de los terrenos, lo cual de nuevo favorece el número de incendios.

En referencia a los datos climáticos la explicación de que no exista una relación entre estas variables y las Hectáreas quemadas e Intensidad puede deberse al hecho de que las variables se han obtenido a través de la media anual de cada distrito forestal y luego se ha realizado la media para los 15 años que representa el abanico temporal del estudio. Al realizar este cálculo estas medias tienden a igualarse y no se pueden observar los casos extremos que son los que verdaderamente pueden influir en la ocurrencia de incendios forestales y afectar en las características de estos.

\section{Discusión}

En este trabajo se analizan las dinámicas de la producción de incendios forestales en los municipios de Galicia, entre 2001 y 2015, y su posible vinculación con factores de índole fundamentalmente socioeconómica. De esta manera, se pretende contribuir al mayor conocimiento de aquellos factores anteriores a la producción de un incendio, que han sido mucho menos abordados en una literatura científica centrada en el análisis de la extinción y sus consecuencias.

No obstante, algunos estudios anteriores que tratan sobre incendios forestales y variables socioeconómicas en Galicia establecen una relación entre estos dos conceptos (Barreal et al., 2011, Balsa \& Hermosilla, 2013; Loureiro \& Barreal, 2015). En este trabajo también se ha 
podido comprobar que las distintas variables socioeconómicas seleccionadas son importantes a la hora de determinar tanto las Hectáreas quemadas como la Intensidad de los incendios. Uno de los principales hallazgos de la presente investigación es que los efectos son distintos dependiendo de la zona de Galicia a la que nos refiramos. Así, a través de la prueba de Chow, se constató la presencia de un cambio estructural en el análisis de los datos. Se realizaron varios modelos para diferentes zonas de la Comunidad, sin la necesidad de usar variables ficticias como se ha hecho en otros estudios (Barreal et al., 2011, 2012).

Las variables climáticas, en cambio, no han sido tan determinantes. Esto se ha debido a la que la media de dichas variables agregada en quince años tiende a igualarse y por tanto no se pueden comprobar los efectos de los casos extremos en grandes incendios forestales (Rodríguez \& Ramil-Rego, 2007; Martínez-Fernández et al., 2013).

El hecho de que exista relación entre las variables socioeconómicas relacionadas con la vulnerabilidad social y los incendios forestales permite centrar la atención en aquellas cuestiones clave para lograr una mayor incidencia en las actuaciones de minimización de su producción y/o prevención de los mismos.

Así, el abandono progresivo del medio rural es uno de los principales problemas que favorecen los incendios forestales (Wigtil et al., 2016, Varela et al., 2007; Rigueiro et al., 2002). A su vez, este lleva asociadas cuestiones sociales (envejecimiento, baja densidad, etc.) y cuestiones económicas (baja renta bruta por habitante, bajo valor catastral, etc.). Es, por ello, importante tomar medidas destinadas, por ejemplo, a mejorar las condiciones de trabajo femenino en el medio rural, reduciendo así el índice de masculinidad, aumentando la densidad de población y disminuyendo el envejecimiento a medio-largo plazo; todas ellas variables que, cómo se ha visto en los modelos anteriores, impactaban sobre los incendios forestales.

Otro aspecto relevante es la falta de gestión del territorio forestal, que lleva asociados la pérdida de valor del monte y el aumento de combustible, con el consecuente incremento del riesgo de incendios (Vilariño, 1998). Una manera de contrarrestar este efecto adverso es revalorizar el territorio forestal, lo cual produce un aumento del valor catastral, minimizando la producción y/o el impacto de los incendios (ya sea en número de Hectáreas quemadas o en su Intensidad). De cara a alcanzar esta revalorización, sería necesario aumentar las inversiones en estas explotaciones buscando además sinergias con otras medidas, como por ejemplo la creación de sistemas de mosaicos agroforestales (Martínez-Fernández et al., 2013). Todo ello conllevaría una mejora de la calidad de vida en las zonas rurales, incidiendo finalmente en variables como la 
densidad de población y la renta por habitante. Otorgando valor al bosque se cambia la percepción que se tiene de los medios forestales y por tanto se pueden reducir los incendios. Hay que tener en cuenta que el monte gallego es un recurso para la obtención de materias primas y también un espacio de suma importancia dentro del sector del turismo (Balsa y Hermosilla, 2013), esto es, el monte tiene un valor intrínseco. Por esta razón, si la población local tomara conciencia de esta realidad, se lograría el objetivo de mantener y conservar estos territorios forestales.

Asimismo, la manera más eficiente de mantener las funciones económicas, sociales y ambientales de una zona es tomar medidas antes de la ocurrencia de un evento catastrófico (Birkmann, 2013): aumentar el gasto en prevención y diseñar estrategias para ello se convierte en una prioridad. Por ejemplo, en lo que respecta a los modelos desarrollados en este artículo, estas medidas pasarían por la gestión de las zonas de interfaz urbano forestal, relacionadas con variables como la proporción diseminados/núcleos y el PIB.

Los trabajos que se llevan a cabo en materia de prevención son competencia de las instituciones públicas, concretamente de la Administración Central del estado. No obstante, estas competencias están transferidas a las Comunidades Autónomas. Por este motivo, para mejorar la gestión de los riesgos naturales y en concreto de los incendios forestales, resulta necesario implicar a las entidades locales, primeras conocedoras de la realidad socioeconómica que afecta a cada uno de sus municipios (Loureiro \& Barreal, 2015). Esto resulta complicado a corto plazo, pero una mayor incidencia en la mejora de la calidad de vida en el medio rural previsiblemente modificaría de manera positiva estas variables de cara a su relación con los incendios forestales. Se detecta la necesidad de establecer modelos de desarrollo sostenible donde se tengan en cuenta los aspectos sociales que destacan como una causa de los incendios forestales.

Los cambios propuestos deben potenciarse a medio-largo plazo, donde se promueva un intercambio entre las diferentes estructuras poblaciones y a la vez se pueda incidir en ciertos comportamientos tradicionales dañinos, asociados a sociedades envejecidas (Balsa-Barreiro \& Hermosilla, 2013). Ello permitiría mejorar los índices de recambio de población activa y la estructura demográfica.

\section{Conclusiones}

La relevancia de los resultados que establecen una relación entre las variables socioeconómicas relacionadas con la vulnerabilidad social y Hectáreas quemadas e Intensidad debe ser tomada en 
consideración por los decisores técnicos y políticos. No solo es necesario actuar sobre las cuestiones climáticas, medioambientales y naturales a la hora de disminuir el riesgo; hay que incidir en todos los aspectos que tienen influencia. Se deben elaborar estrategias de medio-largo plazo que sean complementarias a las labores de prevención, donde se mitiguen los impactos adversos de algunas variables socioeconómicas (como abandono rural, renta baja o envejecimiento). Las investigaciones demuestran esta relación reflejando, por tanto, un problema presente en la sociedad.

Pero ¿qué papel juega la sociedad en los incendios forestales? La capacidad de respuesta de los ciudadanos ante una emergencia depende en gran medida de la concepción que estos tengan del riesgo. Esto incide también en el apoyo a las políticas de gestión forestal y a las acciones llevadas a cabo por los servicios de emergencia. No obstante, aunque, en general los incendios forestales son comúnmente percibidos como un elemento catastrófico y aleatorio, existen dos visiones diferentes que pueden convivir en un mismo individuo:

- El incendio visto como una amenaza a combatir: esta visión aparece en zonas donde existe una relación intensa entre medio urbano y medio natural. En estos casos la percepción es negativa ya que existe una idea de peligro asociada a los incendios y además se tienen en cuenta efectos desfavorables como pérdida de calidad de terrenos, de vegetación, de paisajes forestales, etc.

- El fuego como herramienta de gestión territorial: esta percepción es más habitual en zonas de montaña y territorios rurales con presencia de sector agrícola y ganadero. Esta visión puede conllevar a la expansión de conatos (fuego incipiente), pudiendo provocar incendios forestales de mayor intensidad y extensión.

Como se ha venido demostrando en este artículo, uno de los grandes desafíos es establecer la unión entre todos los factores que intervienen en un incendio forestal, desde la prevención hasta la extinción, entendiendo su comportamiento y minimizando sus efectos. En definitiva, este trabajo ha permitido probar la influencia de las variables socioeconómicas en las Hectáreas quemadas y en la Intensidad de los incendios forestales en Galicia. Sus conclusiones permiten sugerir que, trabajando sobre estas cuestiones, se puede generar un cambio en los efectos destructivos de los incendios de origen antrópico.

Agradecimientos: A la fundación AON y en concreto a Pedro Tomey por su incondicional apoyo.

Declaración responsable: Las/os autoras/es declaran que no existe ningún conflicto de interés con relación a la publicación de este artículo. Las tareas se han distribuido de la siguiente manera: 
el artículo ha sido coordinado por Antonio Rúa y Mercedes Fernández y es parte de la tesis doctoral de Jaime de Diego. Jaime realizó la revisión bibliográfica supervisado por sus directores. Las variables dependientes e independientes a incorporar en los modelos fueron discutidas por los tres autores en función de la revisión de la literatura. La asesoría estadística corrió a cargo el profesor Rúa. La confección, pruebas, depuración de los modelos y análisis de los datos fue realizada por Jaime de Diego, bajo la supervisión de los profesores Rúa y Fernández. Los tres autores participaron en la elaboración de las conclusiones. Mercedes Fernández revisó la edición final del artículo. 


\section{Bibliografía}

Ager, A. A., Evers, C. R., Day, M. A., Preisler, H. K., Barros, A. M., \& Nielsen-Pincus, M. (2017). Network analysis of wildfire transmission and implications for risk governance. PLoS One, 12(3), e0172867. http://www.doi.org/10.1371/journal.pone.0172867

Alonso Climent, I. (2002). Tercer mundo, desarrollo, desastres y tecnología. Una mirada desde la geografía. Serie Geográfica, 10, 11-26.

Ashe, B., Mcaneney, K.J., \& Pitman, A.J. (2009). Total cost of fire in Australia. Journal of Risk Research, 12(2), 121-136.

Ballart, H., Vázquez, I., Chauvin, S., Gladine, J., Plana, E., Font, M., \& Serra, M. (2016). La comunicación del riesgo de incendios forestales. Recomendaciones operativas para mejorar la prevención social. Projecte eFIRECOM (DG ECHO 2014/PREV/13). Ediciones CTFC. Retrieved from http://efirecom.ctfc.cat/docs/Efirecom\%20Recomendaciones\%20ESP_final.pdf

Balsa Barreiro, J., \& Hermosilla, T. (2013). Socio-geographic analysis of the causes of the 2006's wildfires in Galicia (Spain). Forest Systems, 22(3), 497-509.

Barreal, J., Loureiro, M., \& Picos, J. (2012). Estudio de la causalidad de los incendios forestales en Galicia. Economía agraria y recursos naturales, 12(1), 94114. http://www.doi.org/10.7201/earn.2012.01.04

Barreal, J., Loureiro, M., \& Picos, J. (2011). Estudio de la incidencia de los incendios en Galicia: una perspectiva socioeconómica. Revista Galega de Economía, 20, 1-20. Retrieved from https://www.redalyc.org/articulo.oa?id=391/39121275013

Benítez-Badillo, G., Hernández-Huerta, A., Equihua-Zamora, M., Pulido-Salas, M.T., IbáñezBernal, S., \& Mirando-Martín del Campo, L. (2010). Biodiversidad. Atlas del Patrimonio Natural, Histórico y Cultural de Veracruz. Tomo I. México: Universidad Veracruzana.

Bentley, PD., \& Penman, TD. (2017). is there an inherent conflict in managing fire for people and conservation? International Journal of Wildland Fire, 26(6), 455. http://doi.org/10.1071/WF16150

Beramendi, M. (2018, April 15). Galicia lidera el ránking mundial de lugares con más superficie forestal desaprovechada. La Voz de Galicia. Retrieved from https://www.lavozdegalicia.es/noticia/galicia/2018/04/15/galicia-lidera-rankingmundial-lugares-superficie-forestal-desaprovechada/0003_201804G15P8991.htm 
Bergstrand, K., Mayer, B., Brumback, B., \& Zhang, Y. (2015). Assessing the Relationship between Social Vulnerability and Community Resilience to Hazards. Social Indicators Research, 122(2), 391-409.

Birkmann, J. (2013). Measuring vulnerability to natural hazards: Towards disaster resilient societies (Second edition). Tokio \& New York: United Nation University Press.

Bouillon, C., Fernandez Ramiro, M. M., Sirca, C., Fierro Garcia, B., Casula, F., Vila, B., ... Long Fournel, M. (2014). A tool for mapping rural-urban interfaces on different scales, in advances in forest fire research. In D. X. Viegas (Ed.), Advances in forest fire research (pp. 611-625). Imprensa da Universidade de Coimbra. http://www.doi.org/10.14195/978-989-26-0884-6_70 Braña Rey, F. (2015). Imaginarios de monte y fuego. Los incendios forestales en Galicia imagonautas. Revista Interdisciplinaria sobre Imaginarios Sociales, 6, 15-26.

Cardil, A., Molina, D. M., Ramirez, J., \& Vega-García, C. (2013). Trends in adverse weather patterns and large wildland fires in Aragón (NE Spain) from 1978 to 2010. Natural Hazards Earth System Sciences, 13, 1393-1399. https://doi.org/10.5194/nhess-13-1393-2013

Cirella, G. T., lyalomhe, F. O., \& Russo, A. (2016). Vulnerability and risks related to climatic events in urban coastal environments: Overview of actuality and challenges of methodologies and approaches. UPLanD-Journal of Urban Planning, Landscape \& environmental Design, 1(1), 67.

Consejo Económico y Social (CES). (2018). El medio rural y su vertebración social y territorial. Consejo Económico y Social (Informe 01/2018).

COSE Selvicultores. (2015). El problema actual de los incendios forestales en Galicia. Informe de la Confederación de Organizaciones de Selvicultores de España.

Crompton, R., Mcaneney, J., Chen, K., Pielke, R. \& Haynes, K. (2010). Influence of Location, Population, and Climate on Building Damage and Fatalities due to Australian Bushfire. Weather, Climate, and Society, 2(4), 300-310.

De Diego, J.; Rúa, A.; \& Fernández, M. (2019). Designing a Model to Display the Relation between Social Vulnerability and Anthropogenic Risk of Wildfires in Galicia, Spain. Urban Science, 3, 32.

Del Moral Ituarte L., \& Pita López M.F. (2002) El papel de los riesgos en las sociedades contemporáneas. In F. J. Ayala Carcedo \& J. Olcina Cantos (Eds.), Riesgos Naturales (pp. 7586). Barcelona: Ariel. Retrieved from http://titulaciongeografiasevilla.es/contenidos/profesores/publicaciones/archivos/RIESGO-PUBLICACION.pdf 
Donner, W., \& Rodríguez, H. (2008). Population Composition, Migration and Inequality: The Influence of Demographic Changes on Disaster Risk and Vulnerability. Social Forces, 87(2), $1089-1114$.

Elliott, J.R., \& Pais, J. (2010). When Nature Pushes Back: Environmental Impact and the Spatial Redistribution of Socially Vulnerable Populations. Social Science Quarterly, 91(5), 1187-1202.

Fisher, F. M. (1970) Tests of equality between sets of coefficients in two linear regressions. Econometrica, 38(2), 361-366.

Fogel, S.J. (2017). Reducing Vulnerability for Those Who Are Homeless During Natural Disasters. Journal of Poverty, 21(3), 208.

Galiana Martín, L. (2012). Las interfaces urbano-forestales: un nuevo territorio de riesgo en España. Boletín de la Asociación de Geógrafos Españoles, (58), 205-226.

Gómez Nieto I., Martín Isabel M. P., \& Salas Rey F. J. (2015). Análisis del régimen de incendios forestales y su relación con los cambios de uso del suelo en la comunidad autónoma de Madrid (1989-2010). GeoFocus, 16, 281-304.

Gonçalves, A.B., Vieira, A., Leite, F. F., \& Lourenço, L. (2012). Mudanças climáticas e risco de incêndio florestal no ave (noroeste de portugal). Revista Geonorte, Edição Especial, 1(4), 830_ 842.

Guisán, M.C. (2017). La economía de Galicia y España en 2007-2017: diez años de crisis y recuperación. Revista Galega de Economía, 26(1), 103-114 Retrieved from https://www.redalyc.org/pdf/391/39152051009.pdf

Guisán, M.C., \& Aguayo, E. (2009). Empleo y producción en Galicia en el período 20012008. Efectos de la industria y el turismo sobre los sectores de Servicios. Revista Galega de Economía, 18(2). Retrieved from http://www.usc.es/econo/RGE/Vol18_2/castelan/art7c.pdf Haynes K., Handmer J., Mcaneney J., Tibbits A., \& Coates L. (2010). Australian bushfire fatalities 1900-2008: Exploring trends in relation to the 'Prepare, stay and defend or leave early'

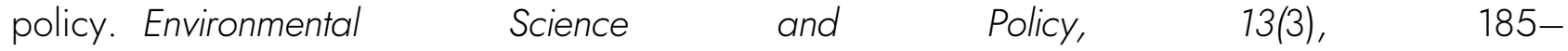
194.. https://doi.org/10.1016/j.envsci.2010.03.002

Hernández, L. (2016). Dónde arden nuestros bosques. Análisis y soluciones de WWF. Madrid: WWF/Adena. Retrieved from http://awsassets.wwf.es/downloads/dondeardennuestrosbosques2016_1.pdf 
lyalomhe, F. (2011). Understanding developing countries vulnerability and adaptation to climate change using theoretical change vulnerability framework. African Journal of Computing and ICT, 4(3), 33-40. Retrieved from

https://www.researchgate.net/publication/282731742_lyalomhe_F_2011_Understanding_devel oping_countries_vulnerability_and_Adaptation_to_climate_change_using_theoretical_change_vul nerability_framework_Afr_Journal_of_Comp_ICTs_Vol_4_No3_Issue_2_pp_33-40

Kocher, S., \& Butsic, V. (2017). Governance of Land Use Planning to Reduce Fire Risk to Homes Mediterranean France and California. Land, 6(2), 24. https://doi.org/10.3390/land6020024

Loureiro, M., \& Barreal, J. (2015). Modelling spatial patterns and temporal trends of wildfires in Galicia (NW Spain). Forest Systems, 24(2), e022. http://dx.doi.org/10.5424/fs/2015242$\underline{05713}$

Martínez-Fernández, J., Chuvieco E., \& Koutsias, N. (2013). Modelling long-term fire occurrence factors in Spain by accounting for local variations with geographically weighted regression. Natural Hazards and Earth System Sciences, 13(2), 311-327. Retrieved from https://search.proquest.com/docview/1315216267.\%20doi:\%2010.5194/nhess-13-311$\underline{2013}$

Molano Martín, F.J., Rodríguez Rodríguez, C., \& Ponte Pintor, J.M. (2007). Informe sobre investigación de incendios forestales en Galicia. A Coruña: Diputación de A Coruña.

Molina, J., Rodríguez Y., Silva, F., \& Herrera, M. (2017). Economic vulnerability of fire-prone landscapes in protected natural areas: application in a Mediterranean Natural Park. European Journal of Forest Research, 136(4), 609-624.

Moreno, J.M. (2014). Evaluación preliminar de los impactos en España por efecto del cambio climático. Boletín CF+S., (38/39), 37-56.

Moritz MA., Batllori E., Bradstock RA., et al. (2014). Learning to coexist with wildfire. Nature, 515(7525), 58. https://doi.org/10.1038/nature13946

Morrow, B.H. (1999). Identifying and Mapping Community Vulnerability. Disasters, 23(1), 1-18.

Muñoz, R. V. (2009). Cambio global e incendios forestales: Perspectivas en la Europa Meridional. Recursos rurais: revista oficial do Instituto de Biodiversidade Agraria e Desenvolvemento Rural (IBADER), (5), 49-54.

Murphy, B. (2005) Enhancing Local Level Emergency Management: The Influence of Disaster Experience and the Role of Households and Neighborhoods. Toronto: ICLR Research. 
Padilla M., \& Vega-García C. (2011). On the comparative importance of fire danger rating indices and their integration with spatial and temporal variables for predicting daily humancaused fire occurrences in Spain. International Journal of Wildland Fire, 20, 46-58.

Paveglio T.B., Edgeley, C.M., \& Stasiewicz, A.M. (2018). Assessing influences on social vulnerability to wildfire using surveys, spatial data and wildfire simulations. Journal of Environmental Management, 213,

(425-

439). https://doi.org/10.1016/j.jenvman.2018.02.068

Paveglio, T., Prato, T., Edgeley, C., \& Nalle, D. (2016). Evaluating the Characteristics of Social Vulnerability to Wildfire: Demographics, Perceptions, and Parcel Characteristics. Environmental Management, 58(3), 534-548.

PLADIGA (2018). Memoria. Plan de Prevención e Defensa Contra os Incendios Forestais de Galicia. Xunta de Galicia, Consellería do medio rural.

Ponte, J.M., \& Bandín, C. (2008). Los incendios forestales en Galicia y su investigación. Estudios penales y criminológicos, 28, 317-341.

Rigueiro, A., Mosquera, M.R., López, L., Pastor, J.C., González, M.P., Romero, R., \& Villarino, J.J. (2002). Reducción del riesgo de incendios forestales mediante el pastoreo del caballo gallego de monte. Cuadernos de la Sociedad Española de Ciencia Forestal, 14, 115-118.

Rodríguez, M. (2018, October 29). Los concellos con más del 5\% de población extranjera caen casi a la mitad en siete años. La Opinión A Coruña. Retrieved from https://www.laopinioncoruna.es/galicia/2018/10/29/concellos-5-poblacion-extranjeracaen/1342459.html

Rodríguez Guitián, M.A., \& Ramil-Rego, P. (2007). Clasificaciones climáticas aplicadas a galicia: Revisión desde una perspectiva biogeográfica. Recursos Rurais, 1(3), 31-53.

Rodríguez, F. de J., Pompa-García, M., Hernández-Díaz, C., \& Juárez-Reyes, A. (2010). Patrón de distribución espacial de la pérdida, degradación y recuperación vegetal en Durango, México. Avances en Investigación Agropecuaria, 14(1), 53-66. Retrieved from http://www.redalyc.org/articulo.oa?id=83716113004

Rowe, J. S., \& Sheard, J. W. (1981). Ecological land classification: a survey approach. Environmental management, 5(5), 451-464. 
San-Miguel-Ayanz, J., Durrant, T., Boca, R., Libertà G., Branco, A., de Rigo, D., ... Leray, T. (2018). Forest Fires in Europe, Middle East and North Africa 2017 (EUR 29318 EN). https://doi.org/10.2760/663443

Sharma, S., \& Pant, H. (2017). Vulnerability of Indian Central Himalayan Forests to Fire in a Warming Climate and a Participatory Preparedness Approach Based on Modern Tools. Current Science, 112(10), 2100.

Stein, S.M., Menakis, J., Carr, M.A., Comas, S.J.; Stewart, S.I., Cleveland, H., Bramwell, L., \& Radeloff, V.C. (2013). Wildfire, wildlands, and people: understanding and preparing for wildfire in the wildland-urban interface- a Forests on the Edge report (Gen. Tech. Rep. RMRS-GTR-299. Fort Collins, CO. U.S. Department of Agriculture, Forest Service, Rocky Mountain Research Station).

Úbeda, X., \& Francos, M. (2018). Incendios forestales, un fenómeno global. Biblio3W, XXIII(1253). Retrieved from http://www.ub.edu/geocrit/b3w-1253.pdf

Varela, E., Calatrava, J., Ruiz-Mirazo, J., Jiménez, R., \& González-Rebollar, J. L. (2007). Valoración económica del pastoreo en términos de costes evitados en labores de prevención de incendios forestales. Presented at the 4th International Wildland Fire Conference.

Vilariño, J. P. (1998). Desarrollo corporativo del sector forestal. Agricultura y sociedad, (85), 1542.

Wigtil, G., Hammer, R.B., Kline, J.D., Mockrin, M.H., Stewart, S.I., Roper, D., \& Radeloff, V.C. (2016). Places where wildfire potential and social vulnerability coincide in the coterminous United States. International Journal of Wildland Fire, 25(8), 896.

Wisner, B., Blaikie, P., Cannon, T., \& Davis, I. (2004). At Risk: Natural Hazards, people's vulnerability and disasters (2nd edition). New York: Routledge. 